\title{
Empirical estimation of present-day Antarctic glacial isostatic adjustment and ice mass change
}

\author{
B. C. Gunter ${ }^{1,2}$, O. Didova ${ }^{1}$, R. E. M. Riva ${ }^{1}$, S. R. M. Ligtenberg ${ }^{3}$, J. T. M. Lenaerts ${ }^{3}$, M. A. King ${ }^{4,5}$, \\ M. R. van den Broeke ${ }^{3}$, and T. Urban 6 \\ ${ }^{1}$ Geoscience and Remote Sensing, Delft University of Technology, P.O. Box 5048, 2600 GA, Delft, the Netherlands \\ ${ }^{2}$ School of Aerospace Engineering, Georgia Institute of Technology, 270 Ferst Dr. NW, Atlanta, GA 30332-0150, USA \\ ${ }^{3}$ Institute for Marine and Atmospheric Research Utrecht, Utrecht University, P.O. Box 80.005, \\ 3508 TA, Utrecht, the Netherlands \\ ${ }^{4}$ School of Geography and Environmental Studies, University of Tasmania, Hobart 7001, Australia \\ ${ }^{5}$ School of Civil Engineering and Geosciences, Newcastle University, Newcastle upon Tyne NE1 7RU, UK \\ ${ }^{6}$ The University of Texas at Austin, Center for Space Research, 3925 West Braker Ln, Ste 200, Austin, TX 78759, USA \\ Correspondence to: B. C. Gunter (brian.gunter@aerospace.gatech.edu)
}

Received: 16 June 2013 - Published in The Cryosphere Discuss.: 16 July 2013

Revised: 24 February 2014 - Accepted: 2 March 2014 - Published: 28 April 2014

\begin{abstract}
This study explores an approach that simultaneously estimates Antarctic mass balance and glacial isostatic adjustment (GIA) through the combination of satellite gravity and altimetry data sets. The results improve upon previous efforts by incorporating a firn densification model to account for firn compaction and surface processes as well as reprocessed data sets over a slightly longer period of time. A range of different Gravity Recovery and Climate Experiment (GRACE) gravity models were evaluated and a new Ice, Cloud, and Land Elevation Satellite (ICESat) surface height trend map computed using an overlapping footprint approach. When the GIA models created from the combination approach were compared to in situ GPS ground station displacements, the vertical rates estimated showed consistently better agreement than recent conventional GIA models. The new empirically derived GIA rates suggest the presence of strong uplift in the Amundsen Sea sector in West Antarctica (WA) and the Philippi/Denman sectors, as well as subsidence in large parts of East Antarctica (EA). The total GIA-related mass change estimates for the entire Antarctic ice sheet ranged from 53 to $103 \mathrm{Gt} \mathrm{yr}^{-1}$, depending on the GRACE solution used, with an estimated uncertainty of $\pm 40 \mathrm{Gt} \mathrm{yr}^{-1}$. Over the time frame February 2003October 2009, the corresponding ice mass change showed an average value of $-100 \pm 44 \mathrm{Gt} \mathrm{yr}^{-1}$ (EA: $5 \pm 38$, WA: $-105 \pm 22$ ), consistent with other recent estimates in the literature, with regional mass loss mostly concentrated in WA.
\end{abstract}

The refined approach presented in this study shows the contribution that such data combinations can make towards improving estimates of present-day GIA and ice mass change, particularly with respect to determining more reliable uncertainties.

\section{Introduction}

Over the past decade, there has been general consensus within the glaciological and geodesy communities that the ice sheet of Antarctica is currently experiencing a significant loss in ice mass on the order of tens to hundreds of gigatons $\left(1 \mathrm{Gt}=10^{12} \mathrm{~kg}\right)$ per year (Chen et al., 2006; Rignot et al., 2008; Horwath and Dietrich, 2009; Jacob et al., 2012; Shepherd et al., 2012). For Antarctica, the mass change estimates from the Gravity Recovery and Climate Experiment (GRACE) have large uncertainties associated with them due to a number of inaccurately known input models (Thompson et al., 2004; Seo et al., 2008; Gunter et al., 2010). Of these, the dominant error comes from the inaccurate knowledge of glacial-isostatic adjustment (GIA), which is the deformation of the solid earth due to the slow return of mantle material that was displaced by the changing ice-ocean load during the last ice age (which peaked globally $\sim 21 \mathrm{kyr}$ ago). The fact that the GRACE mission can only observe the total gravitational accelerations acting on the mission's twin satellites 
means that GRACE measurements are not able to distinguish between accelerations due to mass changes caused by the loss/gain of ice from those accelerations caused by the GIAinduced surface uplift. As a result, the effects of GIA are typically removed in the data processing using modeled values; however, the uncertainty in current GIA models is also on the order of tens of ${\mathrm{Gt} \mathrm{yr}^{-1}}^{-1}$, or on the same scale as the estimated ice mass change (Gunter et al., 2009; Horwath and Dietrich, 2009; King et al., 2012; Velicogna and Wahr, 2013). This is due to the very sparse (in both space and historical time) geophysical and climatological data available for Antarctica, which are required to constrain historical changes in ice history and hence GIA models. This uncertainty in the GRACE estimates makes the monitoring and prediction of current mass loss trends much less reliable and highlights the need to make improvements in the determination of the GIA and ice-mass change signals.

An alternative to forward modeling present-day GIA is to estimate present-day uplift (Wahr et al., 2000) from instrument observations. One approach to accomplishing this involves supplementing GRACE data with estimates of ice elevation (satellite altimetry) and bedrock uplift (GPS). The addition of the altimetry products is particularly important because they track absolute volume changes, as opposed to the absolute mass change measured by GRACE. While these are two completely different observables, they are complementary and permit the separation of the GIA and ice mass loss, given knowledge of ice/rock densities. This is possible because the large density contrast between rock and ice, as well as the large differences in their respective volume changes, allows the altimetry products to better isolate the volume/mass changes associated with surface processes, e.g., glacial thinning. For example, if a given region has decimeter-level annual glacial thinning in addition to $\mathrm{mm} \mathrm{yr}^{-1}$ uplift in the solid-earth due to GIA, the altimetry would predominately observe the height changes due to the glacial thinning; however, the corresponding (large) mass change from the small solid-earth uplift would be clearly observable from GRACE. Previous studies have demonstrated the feasibility of this approach (Wahr et al., 2000; Velicogna and Wahr, 2002), with the first real-data combination produced by Riva et al. (2009). As a joint estimation problem, GIA and ice mass change trends are simultaneously computed, creating a self-consistent set of estimates. In addition, as a data-driven approach, the errors of the input data sets can be used to generate realistic and spatially varying uncertainties of the resulting GIA and mass change estimates through standard error propagation techniques. In the time since the first real-data combination was achieved, several major improvements to the methodology and data sets have taken place, resulting in new estimates of Antarctic GIA and ice sheet mass balance that this paper seeks to highlight.

New contributions of this study include the use of updated data from GRACE and the Ice, Cloud and land Elevation Satellite (ICESat) mission, which have both recently undergone a complete reprocessing that has noticeably improved the data quality compared to previous releases. For the GRACE data, a range of both unconstrained and regularized solutions are evaluated to better categorize the impact that different processing strategies can have on the results. The ICESat data was processed using a recently developed technique involving the use of overlapping footprints (OFPs). The approach was first developed by Slobbe et al. (2008) for a study of the Greenland ice sheet, but has not been applied previously to Antarctica. The OFP approach was expanded and improved for this study, and made use of the latest release of ICESat data (R633). The OFP method has many benefits over standard repeat-track and crossover techniques, and is particularly well-suited to Antarctica due to the high density of laser shots available. The technique also allows for the independent determination of the systematic campaign biases which are present in the ICESat surface height rates, a critical aspect when considering long-term ice sheet volume changes.

Another important contribution of this study is the use of a firn densification model (FDM) that estimates spatial and temporal variations in firn layer temperature, depth, and mass, and which also accounts for penetration, retention, and refreezing of meltwater. Most similar studies to date have relied on a simplified density assumption to convert altimetric heights to mass, often just a constant value. For many regions which experience highly variable accumulation rates as well as glacial thinning and high GIA rates a constant surface density assumption significantly misrepresents the true surface characteristics.

Finally, the GIA component of the data combination was compared against vertical height displacement measurements collected from a network of dozens of permanent GPS ground stations. Such comparisons allowed the various data combinations to be evaluated, both with each other as well as against state-of-the-art GIA models.

This paper will assess the impact of these new developments on the GIA and ice mass change estimates of Antarctica, as well as provide an outlook for future investigations. As will be shown later, the resulting GIA models compare favorably with other modeled estimates, but do suggest some areas, such as the Amundsen Sea sector, may be experiencing much higher uplift rates than previously predicted.

\section{Methodology}

The underlying methodology used to combine the altimetric and gravimetric data sets is adapted from earlier work by Riva et al. (2009), summarized here for convenience. In short, the technique relies on the fact that satellite altimetry measurements primarily observe surface processes, such as accumulation and ablation, whereas the mass change measurements from satellite gravimetry are sensitive to the mass change of both GIA and surface processes. By exploiting the 
difference in density between ice/snow, $\rho_{\text {surf }}$, and the solid earth, $\rho_{\text {rock}}$, the following relationship can be established which relates the vertical height rates of GIA, $\dot{h}_{\text {rock }}$, to the mass, height, and density values for a given location.

$\dot{h}_{\text {rock }}=\frac{\dot{m}_{\text {GRACE }}-\rho_{\text {surf }} \cdot \dot{h}_{\text {ICESat }}}{\rho_{\text {rock }}-\rho_{\text {surf }}}$

A $400 \mathrm{~km}$ Gaussian smoothing is applied to ensure the various components in Eq. (1) have the same spatial resolution, but this is only done after elements with equivalent resolution are first combined (including terms in both the numerator and denominator). For example, the multiplication of the surface density and ICESat height rates is done before applying the smoothing, since these two grids have approximately the same spatial resolution. The smoothing of the GRACE data helps reduce the noisiness of the solutions, but undoubtedly attenuates the signal magnitude. That said, the geolocation of the peak signals should not be significantly affected, and the total mass change should remain the same after smoothing, since the Gaussian filter simply redistributes the signal and conserves the total mass. This redistribution is also why a $400 \mathrm{~km}$ extended integration zone (off the coastline) was used when computing total mass change estimates. How the surface and rock densities are treated will be covered in the next section, along with the consideration of elastic effects.

\section{Data sets}

Several data sets are used to perform the combination as well as validate the results. For this study, the total mass change estimates were derived from GRACE and the surface height trends derived from ICESat. The properties of the surface, i.e., surface mass balance (SMB) and firn layer changes, were taken from Antarctic climate and firn densification models. The solid earth densities were assumed to be $4000 \mathrm{~kg} \mathrm{~m}^{-3}$ for land, transitioning to $3400 \mathrm{~kg} \mathrm{~m}^{-3}$ under the ice-shelves, consistent with Riva et al. (2009). The physical reason for the lower density value in the coastal areas (in particular under the largest ice shelves) is twofold. First, GIA also induces sea level changes, meaning that geoid changes over the ocean will be due to the movement of both rock and water masses. Second, ocean loading will affect the evolution of GIA itself, which has been extensively discussed by Simon et al. (2010). Only the surface heights and surface processes over the grounded ice sheet were used, since these changes do not contribute to mass change over the ice shelves, while the GRACE data were used over both land and ocean regions. The time period under investigation covers the entire ICESat mission period, from February 2003 to October 2009.

\subsection{Gravimetry}

The GRACE mission has collected data on the time-variable nature of Earth's gravity field since its launch in March 2002.
A number of research centers produce monthly gravity field models, using different processing methodologies. A range of gravity models are examined in this study, including those generated by the University of Texas at Austin Center for Space Research (CSR), the GeoForschungsZentrum (GFZ), and Delft University of Technology (TUD). Both RL04 and RL05 solutions were evaluated when available, as well as regularized solutions, i.e., those solutions applying additional spatial filtering or other processing methods to the standard L1 or L2 data products released by the GRACE Science Data System (SDS). Future references to GRACE "unconstrained solutions" refer to the standard monthly gravity field models provided to the public by the CSR and GFZ that have not had such regularization applied. Degree one coefficients were added to all solutions using values generated from the approach of Swenson et al. (2008) (using RL05 GRACE data), and the $\mathrm{C}_{2.0}$ harmonics were replaced with those derived from satellite laser ranging (Cheng and Tapley, 2004). For the RL04 models, the secular trends that are removed from select zonal coefficients were restored (see Bettadpur (2007) for more details), as these rates are believed to mostly represent the effects of GIA (Cheng and Tapley, 2004). These zonal rates are not removed in the RL05 data processing scheme, so no adjustments were needed for the RL05 models.

For all solutions except the Delft Mass Transport (DMT1b) models produced at TUD (Liu et al., 2010), which use a specialized method for the trend estimation (Siemes et al., 2013), a linear trend was estimated using least squares for each harmonic coefficient across the entire time series of monthly models (again, covering only the time period from February 2003 to October 2009). The trend was co-estimated with a bias, annual periodic, and tidal S2 (161 days) periodic terms. Earlier studies (Seo et al., 2008) indicated that additional aliasing may occur at other tidal frequencies, e.g., K2 (1362.7 days); however, an investigation into these showed that only S2 showed a noticeable influence on the long-term trends over Antarctica, particularly for the newer RL05 solutions. Evidence for this is provided in Fig. S1 in the Supplement, which shows the amplitude of the estimated K2 periodic signal in units of equivalent water height (EWH) computed from both a representative GRACE solution (CSR RL04 DDK3 in this case) and the $330 \mathrm{~km}$ Gaussian smoothed SMB estimates from the regional climate model (see Sect. 3.3). The fact that the majority of the areas with larger amplitudes in the GRACE solution (Fig. SM1a) are spatially correlated with those seen in the SMB estimates (Fig. SM1b) suggests that the signal seen in the GRACE data is genuine mass variability at this frequency.

For the unconstrained CSR and GFZ solutions, the estimated long-term trend was then de-striped using an approach similar to that outlined by Swenson and Wahr (2006), but with the filtering parameters described by Chambers and Bonin (2012). Even though these parameters were created with ocean applications in mind, the choice of polynomial 

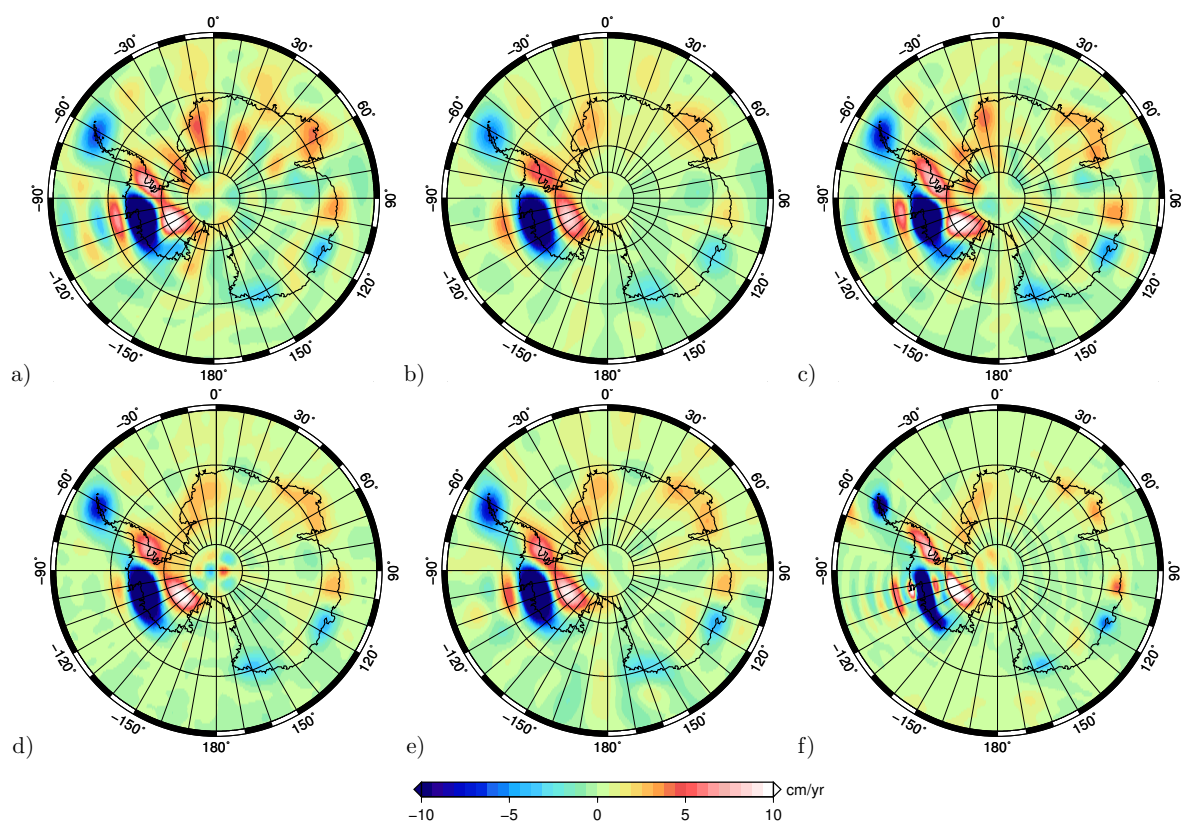

Fig. 1. Long-term mass change trends in units of EWH computed from the following GRACE solutions: (a) CSR RL04, (b) CSR RL04 DDK3, (c) CSR RL05, (d) CSR RL05 regularized, (e) GFZ RL05 DDK5, (f) DMT-1b.

degree (5th order for RL04, 4th order for RL05) and starting degree and order (12 for RL04, 15 for RL05) were found to perform better than other alternative parameters tested, and were therefore used for this study. No de-striping was applied to any of the regularized solutions or to any of the other data sets (altimetry, climate, etc.) used in the combinations.

Several sets of regularized solutions were included in the analysis, to examine the potential impact that different spatial filtering techniques may have on the final results. This included the Wiener-type filter described by Kusche (2007), which was applied to the RL04 (DDK3) and RL05 (DDK5) solutions for both the CSR and GFZ. A recently developed set of filtered solutions developed by Save et al. (2012), utilizing an L-curve method with Tikhonov regularization, was also evaluated (named here "CSR Reg"). Finally, for the DMT1-b solutions, the anisotropic filtering method developed by Klees et al. (2008) is applied after the long-term coefficient trend is estimated (along with bias, annual, and S2 terms).

In total, 10 different GRACE solutions were evaluated, with the geographical plots for a representative selection of these cases shown in Fig. 1. The plots for all 10 solutions can be found in Supplement Fig. S2. As can be seen, the trends for nearly all solutions are quite similar; however, some variations can be seen in terms of the magnitude and resolution of finer features. As will be seen later, these variations will have an important influence of the outcome of the estimated GIA and ice mass change values from the data combinations.

\subsection{Altimetry}

The ICESat mission was the first Earth-orbiting laser altimeter and, while no longer operational, it was able to collect valuable information on the long-term (multi-year) surface height change of Antarctica over a period which directly coincides with when the gravity data from GRACE was collected. The surface height change trends used for this study were computed using the latest release (R633) of ICESat data (Zwally et al., 2011), and were computed using an approach involving OFPs, similar to that described by Slobbe et al. (2008) for Greenland. This is the first time the OFP approach has been applied to Antarctica. The technique is well suited for observing long-term trends at a high spatial resolution, since the co-location of the laser shots used in the height change estimates does not rely on interpolation and/or surface approximations inherent in other techniques, such as crossover and repeat-track analysis. The technique is particularly useful for height change studies in Antarctica due to the high density of laser shots from the near-polar orbit of ICESat. The data processing uses a set of editing criteria to remove outliers, and estimates a custom set of inter-campaign biases, the details of which are outlined below.

\subsubsection{Overlapping footprint approach}

The basic principle of the OFP approach is illustrated in Fig. 2a, where an overlapping footprint pair is defined as any two individual ICESat laser shots whose ground footprint have at least some overlapping area. The technique described by Hughes and Chraibi (2011) was used to determine if the 
a)

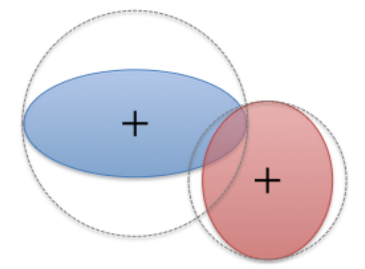

b)

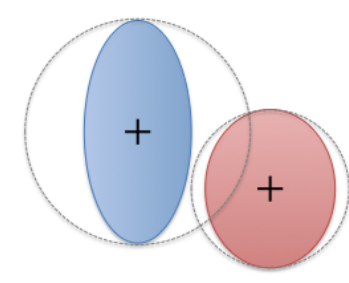

Fig. 2. Illustration of (a) an ICESat overlapping footprint (OFP) pair and (b) near-neighboring shots.

ellipses characterizing any two laser shots physically overlapped, as well as the percentage of overlap if they did. The two laser shots can come from any two ICESat campaigns and are not restricted to ascending or descending tracks; however, OFPs within the same campaign are excluded in this study due to the higher uncertainties they introduce. The height change ( $\mathrm{d} h$ ) from an OFP pair is divided by the time difference $(\mathrm{d} t)$ of the two shots to compute a height change rate $(\mathrm{d} h / \mathrm{d} t)$. To reduce the impact of slope effects, the degree of overlap can be used as an editing criterium so that the center of the two footprint ellipses is as close as possible. This option will be used in the next section when estimating the inter-campaign biases.

To find potential OFPs, the maximum radius for each campaign (the footprint radius is not constant over time) is first determined based on all available shots. Any two shots whose centers are closer than the total sum of their respective campaign radii were considered OFP candidates. Depending on the shape and orientation of the two laser footprints, it is possible that two footprints can be close enough for their circumscribing circles to overlap without the actual footprint ellipses overlapping, as illustrated in Fig. 2b. These neighboring shots in Fig. $2 \mathrm{~b}$ offer the same information content as those in Fig. 2a, since the shot centers are still within twice the (maximum) semi-major axis distance from each other in both scenarios. As such, the ICESat-derived surface height trends used later include these neighboring shots, termed here "near-neighboring" (NNs) shots, to distinguish them from the physically overlapping OFPs. Approximately 151 million total OFP/NN shots were used, of which 76 million were NNs. Unless otherwise noted, future references to OFPs will imply that both OFP and NN pairs are included.

The original full set of R633 laser shots used in the analysis was edited using standard quality flags as well as other criteria, such as the use of only single peak shots, a maximum gain value of 150 , and a maximum co-elevation angle of $0.45^{\circ}$. In addition, any $\mathrm{d} h / \mathrm{d} t$ values computed from individual OFP/NN pairs greater than $12 \mathrm{~m} \mathrm{yr}^{-1}$ were excluded, as this is assumed to be larger than most known glacial thinning or ablation processes (Pritchard et al., 2009). A linear trend in time (without annual terms) was fit using least squares across all $(\mathrm{d} h, \mathrm{~d} t)$ pairs satisfying the editing criteria within
$20 \times 20 \mathrm{~km}$ area blocks, with the uncertainties determined by scaling the formal error from the least squares regression by the estimated variance of unit weight (EVUW) computed from the post-fit residuals (Strang and Borre, 1997). This EVUW scaling also helps to account for errors due to any seasonal variations that might be present. The estimated $\mathrm{d} h / \mathrm{d} t$ values from this process are shown in Fig. 3a, with the corresponding uncertainties in Fig. 3b. When integrated only over the grounded ice sheet, using the boundaries defined by Zwally et al. (2012), the total volume change is approximately $-109 \pm 68 \mathrm{~km}^{3} \mathrm{yr}^{-1}$. Most of the largest uncertainties are located in areas of steep topography, frequent cloud cover, and/or poor measurement sampling, and include regions such as the Transantarctic Mountains, Amundsen Sea sector, and the Antarctic Peninsula, among others.

\subsubsection{Estimation of campaign biases}

The ICESat laser shots are known to have a systematic bias in them that can introduce $\mathrm{cm}$-level errors if neglected (Gunter et al., 2009). To minimize the effect of these campaignspecific biases, an approach to estimate their magnitude was adopted using a low-precipitation zone (LPZ) in East Antarctica (EA), along the same lines as Gunter et al. (2010) and Riva et al. (2009). While other techniques exist in the literature to estimate these campaign biases (Urban and Schutz, 2005; Siegfried et al., 2011; Ewert et al., 2012; Borsa et al., 2014), use of the LPZ offers several advantages as a calibration zone. First, the LPZ is one of the driest places on Earth and gets very little precipitation and, hence, surface height change. Second, it is a large area, which helps improve the reliability of the results. The region is also local to Antarctica, whereas many other techniques are based on regions in other parts of the world. Finally, the density of ICESat ground tracks is highest in the polar regions, meaning many more observations can go into the estimation of the biases. The exact region used to estimate the campaign biases is shown in Fig. 4 and was derived using output from the regional climate model to be discussed in Sect. 3.3. In particular, the region corresponds to an area that is estimated to have less than $21.9 \mathrm{~mm} \mathrm{EWH} \mathrm{yr}^{-1}$ of average yearly solid precipitative flux, a value chosen by trial-and-error to create a continuous low-precipitation zone that is sufficiently isolated from areas of steep topography.

Using this LPZ, a select set of ICESat measurements were used to precisely estimate the biases. One of the advantages of the OFP approach is that the degree of overlap between two laser shots can be tuned to a specific range. With a higher overlap criterion, the shots have more coincident ground coverage, but at the expense of reducing the number of OFPs used, since fewer shots will satisfy the criterion. For the determination of the campaign bias, it was important that the shots involved in the OFPs have high levels of overlap, to reduce any potential errors caused by changes in the surface topography within the footprint area. As such, the OFPs used 

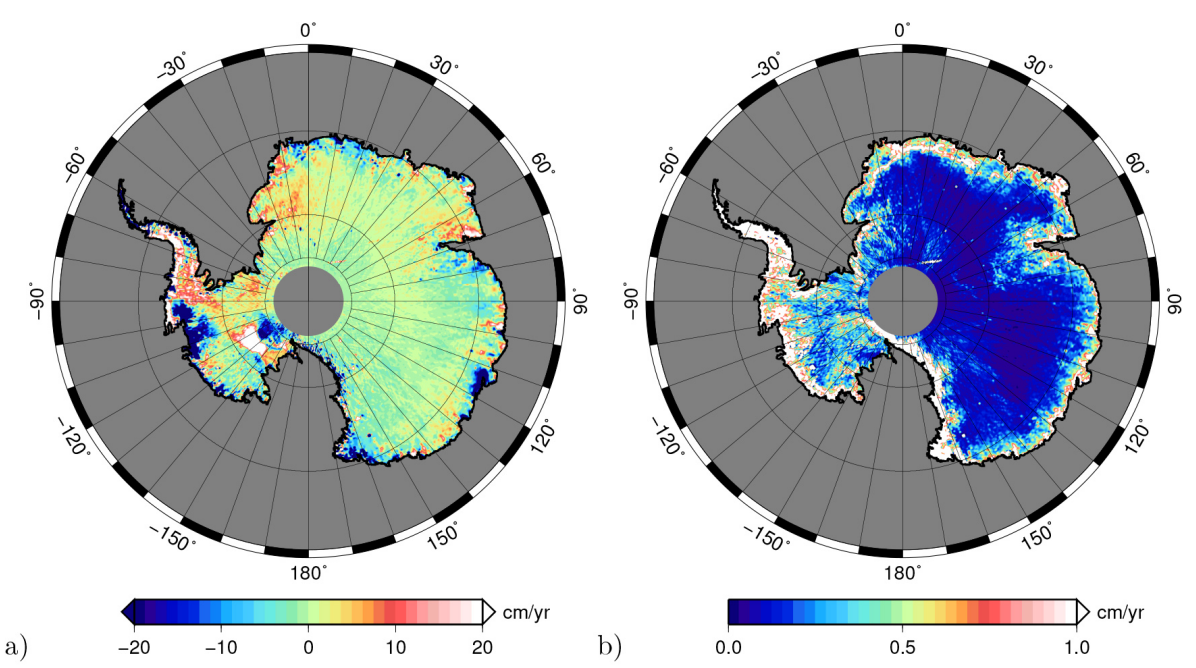

Fig. 3. (a) ICESat $\mathrm{d} h / \mathrm{d} t$ estimates from the OFP approach and (b) corresponding uncertainties.

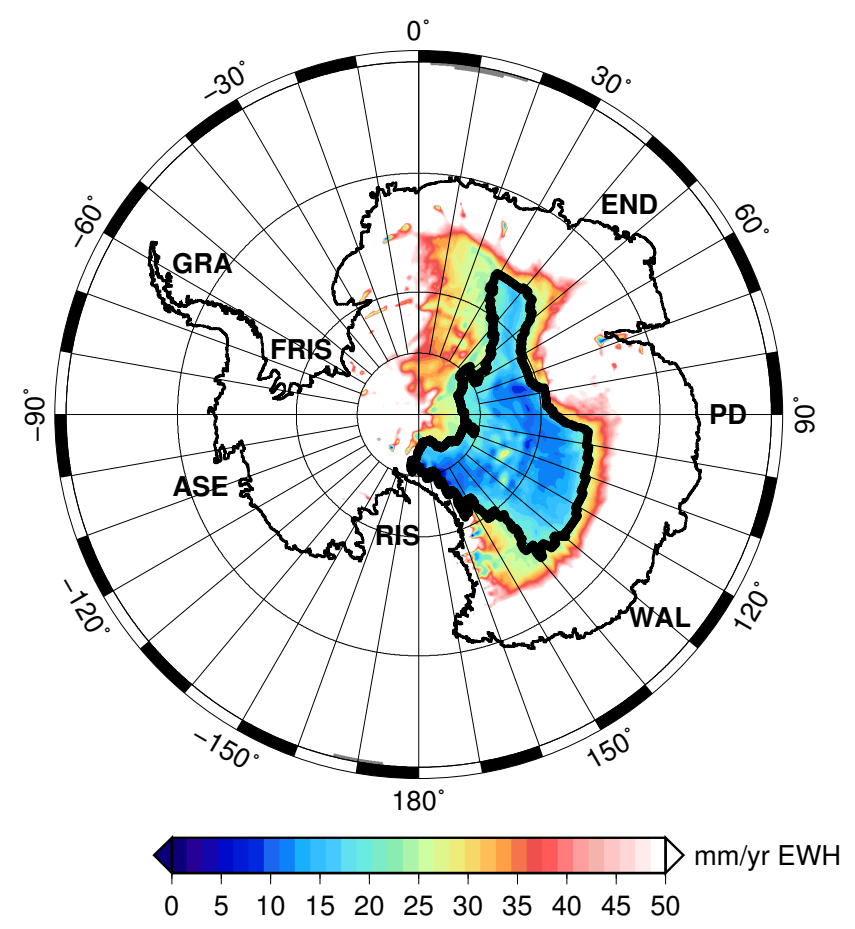

Fig. 4. Outline of the low-precipitation zone (LPZ; black line) overlaid onto estimates of average yearly solid precipitative flux in units $\mathrm{mm} \mathrm{EWH} \cdot \mathrm{yr}^{-1}$, together with the following location indicators: Amundsen Sea (ASE), Graham Land (GRA), Filchner Ronne Ice shelf (FRIS), Enderby Land (END), Philippi/Denman (PD), Wilkes/Adelie Land (WAL), Ross Ice shelf (RIS).

for the bias estimates were required to have at least an $80 \%$ overlap with one or both of the laser shots. In addition, any $\mathrm{d} h$ values greater than $1 \mathrm{~m}$ were considered outliers and excluded (this overlap and dh editing criteria were only used for the determination of the campaign biases). A time series

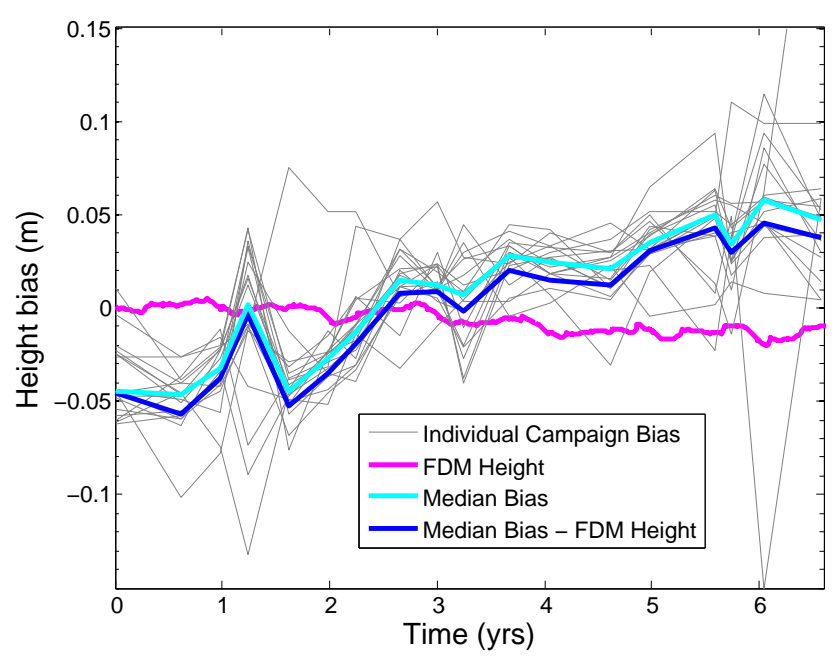

Fig. 5. Illustration of the ICESat campaign biases determined over the LPZ for each individual campaign (grey), the median value (cyan), and the median minus the surface deformation (blue) predicted from the firn densification model (FDM; magenta).

of the least median of squares of the remaining $\mathrm{d} h$ values was created, using each campaign as a reference, for a total of 18 different bias profiles (gray lines in Fig. 5). For example, the bias profile using campaign $3 \mathrm{~b}$ would consist of $\mathrm{d} h$ values from the OFP combinations $1 a-3 b, 2 a-3 b, 2 b-3 b$, etc. The mean of each profile was removed before taking the median value at each time step (cyan). To investigate the influence of possible accumulation or compaction in the LPZ, the firn densification model (Sect. 3.3) was used to predict any surface change of the firn. The model did suggest a small surface lowering over the LPZ, on the order of $-0.15 \mathrm{~cm} \mathrm{yr}^{-1}$ (magenta), and this value was removed from the median values to arrive at the final campaign bias estimates (dark blue) shown 

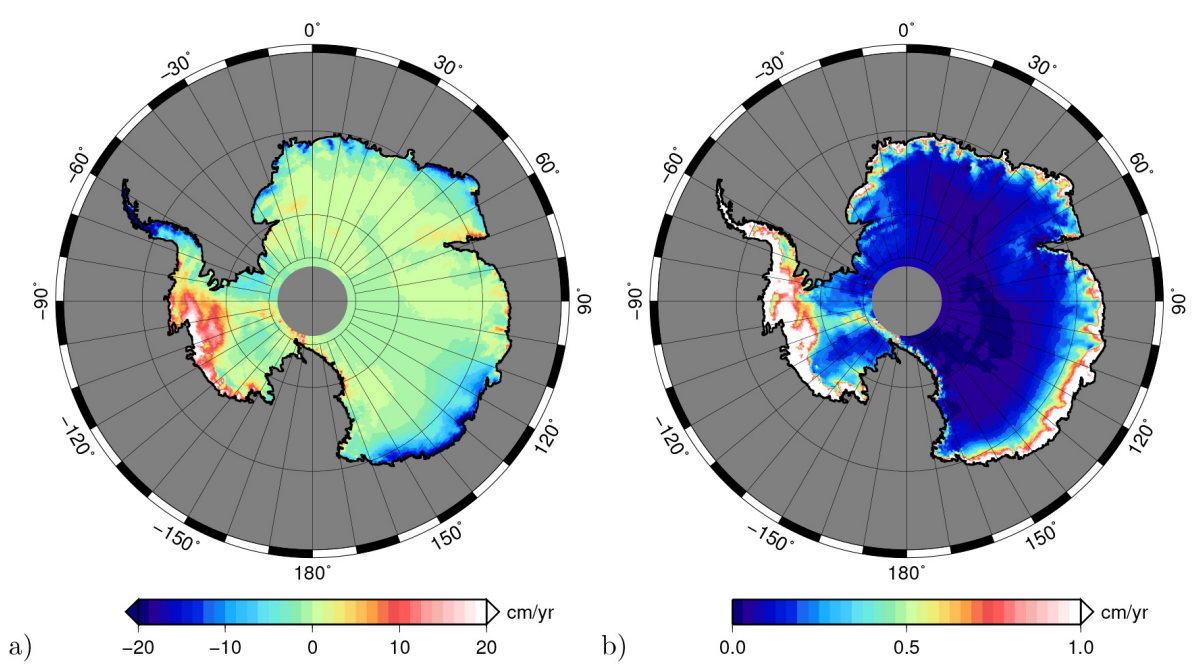

Fig. 6. (a) Firn densification model (FDM) surface height velocities and (b) corresponding uncertainties.

in Table 1. Standard deviations for each campaign bias are also provided in the table. There is a small amount of variation in the biases from campaign to campaign, but the overall trend on the bias estimates is $1.58 \pm 0.08 \mathrm{~cm} \mathrm{yr}^{-1}$. This is generally consistent with the earlier $2.0 \mathrm{~cm} / \mathrm{yr}$ bias estimates computed using mean sea surface comparisons (Gunter et al., 2009) as well as other estimates in the literature (Urban and Schutz, 2005; Siegfried et al., 2011; Ewert et al., 2012); however, these previous bias estimates used earlier ICESat data releases, so are not directly comparable to the estimates of this study. The G-C corrections to the ICESat data described by Borsa et al. (2014) were not applied, as this is a relatively new development, but since the biases computed for this study are calibrated to the LPZ, this should not have a significant influence on the results assuming the G-C corrections essentially manifest themselves as campaign dependent biases (e.g., as shown in Table 1 of Borsa et al., 2014). Also note that because the mean was removed from the individual profiles the values represent the bias offset with respect to the midpoint of the ICESat mission lifetime. The estimated biases were removed from the individual laser shots involved in the height change calculation for each OFP, i.e., before the trend-fitting by blocked area discussed in the previous section.

\subsection{Climate data}

In order to separate the deformation caused by surface processes (ice, firn) from those of the solid-earth (GIA), both the volume and mass change of the ice sheet needs to be known. There are many complex processes at work that complicate the determination of these quantities, including regional variations in temperature, accumulation, and firn compaction. To account for these, the output of the RACMO2 regional atmospheric climate model is used, which is driven by the latest atmospheric reanalysis data from the European Cen-
Table 1. Estimated ICESat campaign biases and uncertainties by campaign.

\begin{tabular}{rllcrl}
\hline Campaign & Start Date & End Date & \# Days & Bias $(\mathrm{m})$ & $\sigma(\mathrm{m})$ \\
\hline 1a/b & $2003-02-20$ & $2003-03-29$ & 38 & -0.046 & 0.017 \\
2a & $2003-09-25$ & $2003-11-19$ & 55 & -0.057 & 0.015 \\
2b & $2004-02-17$ & $2004-03-21$ & 34 & -0.038 & 0.017 \\
2c & $2004-05-18$ & $2004-06-21$ & 35 & -0.004 & 0.047 \\
3a & $2004-10-03$ & $2004-11-08$ & 37 & -0.053 & 0.034 \\
3b & $2005-02-17$ & $2005-03-24$ & 36 & -0.035 & 0.023 \\
3c & $2005-05-20$ & $2005-06-23$ & 35 & -0.019 & 0.024 \\
3d & $2005-10-21$ & $2005-11-24$ & 35 & 0.008 & 0.020 \\
3e & $2006-02-22$ & $2006-03-28$ & 34 & 0.009 & 0.013 \\
3f & $2006-05-24$ & $2006-06-26$ & 33 & -0.002 & 0.026 \\
$3 \mathrm{~g}$ & $2006-10-25$ & $2006-11-27$ & 34 & 0.020 & 0.014 \\
$3 \mathrm{~h}$ & $2007-03-12$ & $2007-04-14$ & 34 & 0.015 & 0.010 \\
3i & $2007-10-02$ & $2007-11-05$ & 37 & 0.012 & 0.014 \\
3j & $2008-02-17$ & $2008-03-21$ & 34 & 0.031 & 0.013 \\
3k & $2008-10-04$ & $2008-10-19$ & 16 & 0.043 & 0.029 \\
2d & $2008-11-25$ & $2008-12-17$ & 23 & 0.029 & 0.025 \\
2e & $2009-03-09$ & $2009-04-11$ & 34 & 0.045 & 0.056 \\
2f & $2009-09-30$ & $2009-10-11$ & 12 & 0.037 & 0.055 \\
\hline
\end{tabular}

tre for Medium-Range Weather Forecasts (ECMWF), ERAInterim, for the period 1979-2010 and run at a horizontal resolution of $27 \mathrm{~km}$ (Lenaerts et al., 2012). In conjunction with the time-varying estimates of SMB from RACMO2, which is the sum of mass gains (precipitation) and mass losses (surface runoff, sublimation, and drifting snow erosion) at the ice sheet surface, a firn densification model (Ligtenberg et al., 2011) is also used, which is forced at the surface with the 6-hourly climate output of RACMO2. The FDM provides temporal surface height changes due to SMB variations, liquid water processes (snowmelt, percolation, refreezing, and runoff), and firn compaction. Figure 6 shows the total surface height rate, and associated uncertainties, as derived from the FDM model over the study period. It is important to note that the FDM of Fig. $6 \mathrm{~b}$ only represents the surface height 
changes of the firn, and does not reflect changes due to either the solid earth or ice dynamics. Furthermore, the mass change of the firn over time, $\dot{m}_{\text {firn }}$, is derived from the SMB, which is a separate product generated from RACMO2, although both the FDM and SMB estimates are inherently linked.

Two basic assumptions were made to account for height differences that were found to exist between the altimetry measurements and the FDM. First, the uncertainties of the height estimates derived from the ICESat and FDM data sets were defined over each approximately $20 \mathrm{~km} \times 20 \mathrm{~km}$ grid cell as

$\sigma_{\mathrm{h}}=\sqrt{\sigma_{\text {ICESat }}^{2}+\sigma_{\mathrm{FDM}}^{2}}$,

using the standard deviations shown in Figs. 3 and 6. In order to convert the volume changes derived from the ICESat data into mass, the density of the volume change needs to be known. Because RACMO2 only models firn processes, any negative differences between the ICESat and FDM surfaces that were greater than $2 \sigma_{\mathrm{h}}$ for any given grid cell were assumed to be the result of ice dynamics (glacier thinning), and the density assigned to this volume loss was that of ice $\left(917 \mathrm{~kg} \mathrm{~m}^{-3}\right)$. Similarly, any positive height differences beyond the $2 \sigma_{\mathrm{h}}$ level were attributed to an underestimation of SMB by RACMO2 and given a density closer to that of snow using a static density profile similar to that of (Kaspers et al., 2004), illustrated in Fig. SM3. The justification for the densities assigned to positive height differences is shown in Fig. 7. This plot shows the derived density (Fig. 7c) computed from those regions where the (GRACE - SMB) differences were greater than $20 \mathrm{~kg} \mathrm{~m}^{-2} \mathrm{yr}^{-1}$ and the (ICESat - FDM) were greater than $6 \mathrm{~cm} \mathrm{yr}^{-1}$. The resulting densities in Fig. 7c are predominantly in the 350$600 \mathrm{~kg} \mathrm{~m}^{-3}$ range, with a mean value of $381 \mathrm{~kg} \mathrm{~m}^{-3}$, suggesting that the use of snow densities for these positive height anomalies is reasonable. Note that the Kamb Ice stream region in West Antarctica (WA) was not included in the comparisons of Fig. 7. The Kamb Ice stream is a special area where no ice discharge takes place, and the positive height change is assumed to be a build-up of ice (glacier thickening). For this reason, the (positive) height differences in this area were assigned a density of $917 \mathrm{~kg} \mathrm{~m}^{-3}$, and the area was the only location where the default density rules of positive or negative height differences were not applied. If the height differences between ICESat and the FDM fell within $2 \sigma_{\mathrm{h}}$, the height measurements were considered to be within the uncertainty of the data sets, and the volume/mass of the difference was neglected. It is important to note that these assumptions only deal with potential residual signal observed between ICESat and the FDM. The majority of the surface mass changes come directly from the SMB estimates (i.e., $\dot{m}_{\text {firn }}$ ) derived from RACMO2. As such, the utilization of the SMB and FDM in the combination approach required a mod- ification of Eq. (1):

$$
\dot{h}_{\text {rock }}=\frac{\dot{m}_{\text {GRACE }}-\left[\left(\dot{h}_{\text {ICESat }}-\dot{h}_{\text {firn }}\right) \cdot \rho_{\alpha}+\dot{m}_{\text {firn }}\right]}{\rho_{\text {rock }}-\rho_{\alpha}},
$$

where

$$
\rho_{\alpha}= \begin{cases}917 \mathrm{~kg} \mathrm{~m}^{-3}, & \text { if } \dot{h}_{\text {ICESat }}-\dot{h}_{\text {firn }}<0 \\ & \text { and }\left|\dot{h}_{\text {ICESat }}-\dot{h}_{\text {firn }}\right|>2 \sigma_{\mathrm{h}} \\ \rho_{\text {surf }}, & \text { if } \dot{h}_{\text {ICESat }}-\dot{h}_{\text {firn }}>0 \\ & \text { and }\left|\dot{h}_{\text {ICESat }}-\dot{h}_{\text {firn }}\right|>2 \sigma_{\mathrm{h}} \\ 0, & \text { otherwise. }\end{cases}
$$

In words, this equation essentially takes the mass change associated with surface processes and subtracts this from the total mass change signal observed from GRACE. The remainder represents mass change due to GIA, which is converted to uplift using the assumed rock density (or density difference between rock and ice/firn, if applicable). The altimetry data, combined with the surface height changes from the FDM, primarily accounts for the changes due to ice dynamics, and the SMB model mostly accounts for the mass changes of the firn, with additional contributions from the altimetry when the observed/predicted surface heights from the ICESat and FDM data are sufficiently different (i.e., $>2 \sigma_{\mathrm{h}}$ ).

It should be noted that, in the combination, an elastic correction is made for the load represented by the right-hand side of the numerator in Eq. (3), i.e., for the surface mass variations computed from ICESat and the SMB data. This correction ultimately has a negligibly small influence on the final results, but is done in the interest of completeness.

\subsection{Vertical site-displacements}

The output from the combination represented by Eq. (3) is a vertical rate associated with GIA over Antarctica, hereafter referred to as the empirical rates. In particular, this rate refers to the rate of solid-earth uplift due to GIA, as opposed to the change in the geoid also associated with GIA, with the subsequent use of the term "GIA rate" implying only this solid-earth uplift. While a map of these values can be compared against other GIA models in an attempt to assess its accuracy, an alternative approach is to compare the empirical rates with those observed by ground-based GPS stations. For this study, vertical displacement rates for up to 35 GPS stations were used for the comparisons to be shown later. The processing of the GPS data followed the approach of Thomas et al. (2011), and includes data from both campaign and permanent stations. Elastic deformation effects were accounted for using the model of Thomas et al. (2011) based on ice mass flux observations (Rignot et al., 2008) with the exception of sites in the northern Antarctic Peninsula where the elastic model does not accurately reproduce near-field displacements. In this region, we therefore follow Thomas et al. (2011) in adopting velocities for the period before 2002 as upper bounds on millennial-scale GIA. At the remaining sites the elastic corrections are generally small (typically 

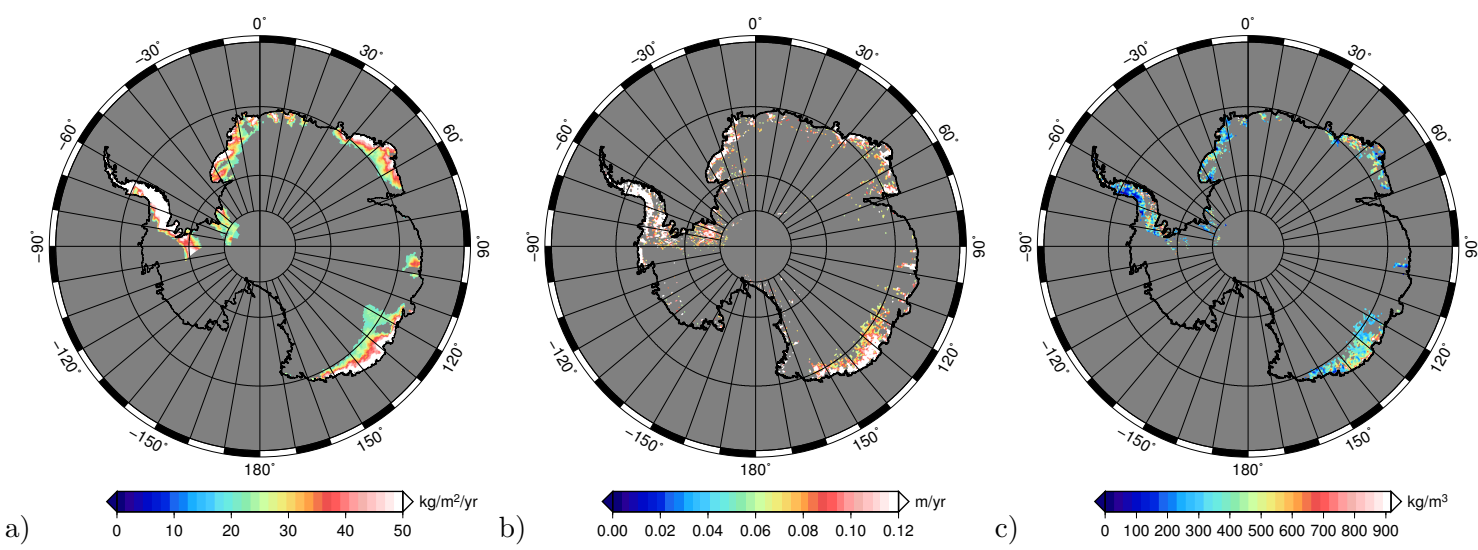

Fig. 7. (a) $\left(\right.$ GRACE-SMB) $>20 \mathrm{~kg} \mathrm{~m}^{-2} \mathrm{yr}^{-1}$, (b) (ICESat-FDM) $>6 \mathrm{~cm} \mathrm{yr}^{-1}$, (c) derived density (mean $381 \mathrm{~kg} \mathrm{~m}^{-3}$ ).

$<0.3 \mathrm{~mm} \mathrm{yr}^{-1}$ ) due to their location in the far field of the dominant ice mass changes within the Amundsen Sea coast and the northern Antarctic Peninsula. Ice mass loading varied non-linearly over the GPS data period and this is not reflected in the elastic model, but for sites outside the northern Antarctic Peninsula this loading is largely due to accumulation fluctuations, and they generally induce small and largely sitespecific biases in the elastic model.

Following a similar approach as Whitehouse et al. (2012), comparisons with the GPS data were done by computing the weighted root-mean-square of the residuals (WRMS) between the vertical empirical or modeled rates and those observed from the GPS stations $(i)$ :

$\mathrm{WRMS}=\sqrt{\frac{\sum w_{i} \cdot\left(\dot{h}_{\mathrm{rock}}-\dot{h}_{\mathrm{GPS}}\right)^{2}}{\sum w_{i}}}$,

where the weight,

$w_{i}=\frac{1}{\sigma_{\mathrm{GPS}}^{2}+\sigma_{\mathrm{rock}}^{2}}$

incorporates both the uncertainty of the individual GPS stations $\left(\sigma_{\mathrm{GPS}}\right)$ as well as the uncertainty of the GIA estimate $\left(\sigma_{\text {rock }}\right.$, described later in Sect. 5.1) at the station location. The uncertainties for the GPS stations ranged from $<0.3 \mathrm{~mm}$ (indicated by large symbols in Fig. 10), to $0.3-1.5 \mathrm{~mm}$ (medium symbols), and $>1.5 \mathrm{~mm}$ (small symbols). Additional details of the comparisons with the GPS displacements will be discussed later in Sect. 5.

\section{GIA bias correction}

One of the early observations from the combination results was the presence of a mm-level bias in the empirically derived GIA rates. Earlier investigations into this suggested that the cause of this bias could come from several sources (Gunter et al., 2010). For example, if there exists a secular trend in the geocenter motion (degree one coefficients), then any $Z$ component rate would be unaccounted for in this analysis. The uncertainty in the determination of $\mathrm{C}_{2,0}$ (related to Earth's oblateness) from GRACE has been recognized for some time, and it is why values from satellite laser ranging are still recommended to be used in place of those found in the official data products. Any trend or other inconsistency in the coefficient values used for $\mathrm{C}_{2,0}$ would translate into a rate bias for Antarctica. Errors in the ICESat campaign bias could also contribute to the differences seen, as would any inconsistency in reference frames used by the various data sets. It is important to note that every $1 \mathrm{~mm}$ of offset in the GIA rates over the entire continent would translate into approximately $50 \mathrm{Gt} \mathrm{yr}^{-1}$ of solid-earth mass change, so while the magnitude of the offset is small, its impact on the solution can be significant.

To address the issue of potential offsets in the solutions, use was made again of the LPZ shown in Fig. 4. The rate of GIA in this region is expected to be very small, i.e., significantly less than the unknown bias offset caused by the various sources discussed above. As such, the LPZ is used as a calibration area, where both the mean surface height change (Sect. 3.2.2) and subsequent GIA is assumed to be zero in that region. In terms of a practical implementation, this is accomplished by computing the mean value over the LPZ of the smoothed $\dot{h}_{\text {rock }}$ values generated from Eq. (3). This mean value, termed the "LPZ GIA bias", is then subtracted from all GIA values uniformly. The magnitude of the LPZ GIA bias for each case investigated is shown in Table 2. Subsequent references to the empirical GIA rates derived from the combination approach imply that this LPZ GIA bias has been removed.

Calibrating the solutions to the LPZ provides a simple but effective way to deal with the range of bias contributors (i.e., geocenter, reference frame, campaign bias, etc.) that are currently not known at the mm-level or less. Taking geocenter as an example, it was earlier mentioned that the degree one coefficients from Swenson et al. (2008) were added to the 


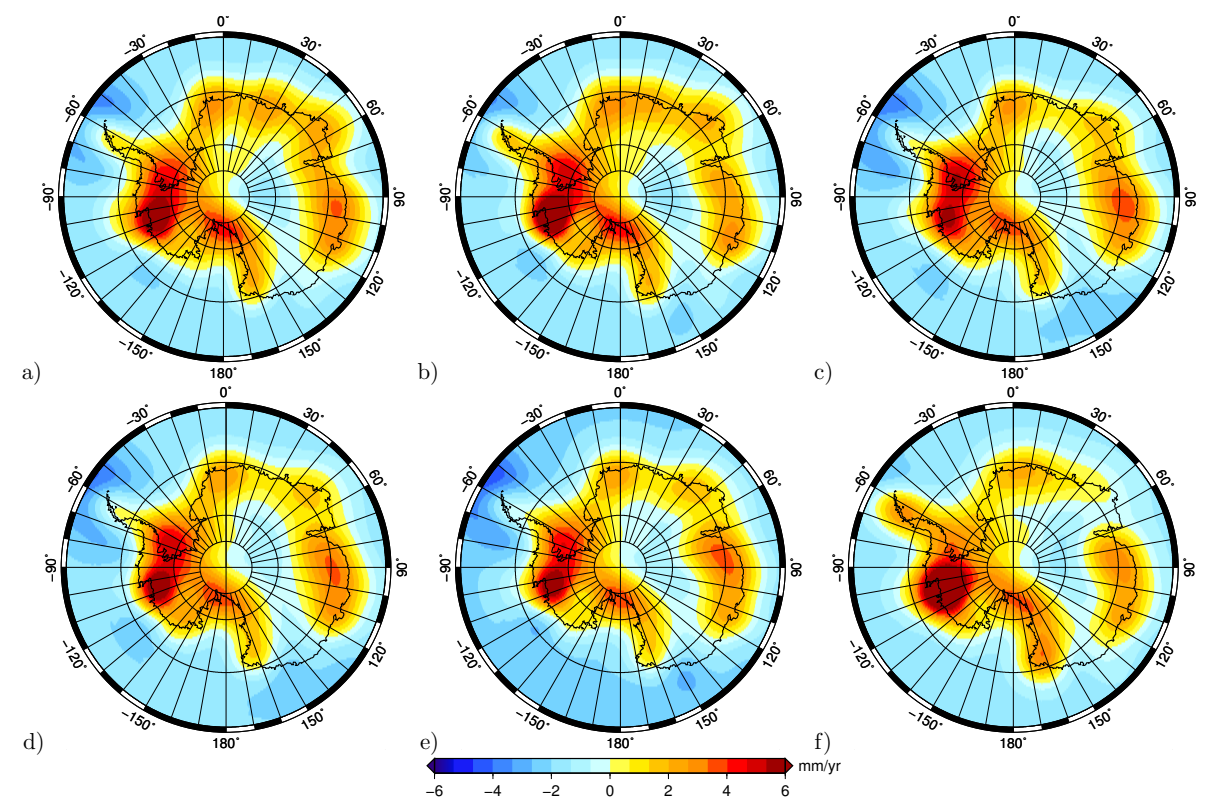

Fig. 8. Estimated empirical GIA vertical rates computed from the combination approach of Eq. (3) and using the following GRACE solutions: (a) CSR RL04, (b) CSR RL04 DDK3, (c) CSR RL05, (d) CSR RL05 regularized, (e) GFZ RL05 DDK5, (f) DMT-1b.

Table 2. Estimates of the mass change components derived from the data-driven approach. Uncertainties are 1- $\sigma$. Also provided is the maximum spherical harmonic degree and order of the original GRACE solution used.

\begin{tabular}{|c|c|c|c|c|c|c|c|c|c|c|c|c|}
\hline \multirow[b]{2}{*}{ Solution } & \multirow{2}{*}{$\begin{array}{r}\text { Max } \\
\text { sph. harm. } \\
\text { deg } \times \text { ord }\end{array}$} & \multicolumn{2}{|c|}{ LPZ bias } & \multicolumn{3}{|c|}{$\begin{array}{l}\text { Total est. mass change } \\
\text { from GRACE }\left(\mathrm{Gt} \mathrm{yr}^{-1}\right)\end{array}$} & \multicolumn{3}{|c|}{ Estimated GIA $\left(\mathrm{Gt} \mathrm{yr}^{-1}\right)$} & \multicolumn{3}{|c|}{$\begin{array}{c}\text { Ice mass change, } \\
\text { GRACE - GIA }\left(\mathrm{Gt} \mathrm{yr}^{-1}\right)\end{array}$} \\
\hline & & $\mathrm{mm} \mathrm{yr}^{-1}$ & $\mathrm{~mm} \mathrm{yr}^{-1} \mathrm{EWH}$ & EA & WA & AIS & EA & WA & AIS & EA & WA & AIS \\
\hline CSR RL04 & 60 & 1.8 & 1.4 & 57 & -71 & -13 & 52 & 34 & 87 & 5 & -105 & -100 \\
\hline CSR RL04 DDK3 & 60 & 1.7 & 1.0 & 53 & -66 & -13 & 48 & 40 & 87 & 5 & -105 & -100 \\
\hline CSR RL05 & 60 & 1.9 & 1.7 & 42 & -77 & -35 & 37 & 28 & 65 & 5 & -105 & -100 \\
\hline CSR RL05 DDK5 & 60 & 1.9 & 1.7 & 42 & -78 & -36 & 37 & 27 & 64 & 5 & -105 & -100 \\
\hline CSR RL05 Reg & 120 & 1.9 & 1.7 & 42 & -78 & -36 & 36 & 27 & 63 & 5 & -105 & -100 \\
\hline GFZ RL04 & 120 & 1.7 & 0.9 & 64 & -62 & 2 & 60 & 43 & 103 & 4 & -105 & -101 \\
\hline GFZ RL04 DDK3 & 120 & 1.6 & 0.6 & 58 & -59 & -1 & 53 & 46 & 100 & 5 & -105 & -101 \\
\hline GFZ RL05 & 90 & 2.1 & 2.3 & 41 & -86 & -45 & 36 & 18 & 54 & 5 & -104 & -99 \\
\hline GFZ RL05 DDK5 & 90 & 2.1 & 2.4 & 39 & -85 & -47 & 33 & 19 & 53 & 5 & -104 & -99 \\
\hline DMT-1b & 120 & 1.6 & 0.6 & 41 & -58 & -17 & 35 & 48 & 82 & 6 & -106 & -100 \\
\hline IJ05 & & & & & & & 33 & 41 & 74 & & & \\
\hline ICE-5G & & & & & & & 53 & 48 & 101 & & & \\
\hline $\mathrm{W} 12 \mathrm{a}$ & & & & & & & 5 & 46 & 51 & & & \\
\hline Riva09 & & & & & & & 59 & 33 & 92 & & & \\
\hline Est. uncertainties & & & & 18 & 6 & 19 & 34 & 21 & 40 & 38 & 22 & 44 \\
\hline
\end{tabular}

GRACE data, although there exist many alternative estimates for these coefficients, such as those from Cheng et al. (2011) and others, which often produce estimates of differing phase and amplitude. As an illustration, the spatial variability in the estimated trends between the Swenson et al. (2008) and Cheng et al. (2011) coefficients can be seen in Fig. SM4, expressed in units of $\mathrm{mm} \mathrm{yr}^{-1} \mathrm{EWH}$. When either of these degree one solutions is used in the combination approach and calibrated over the LPZ (i.e., subtracting the LPZ GIA bias),

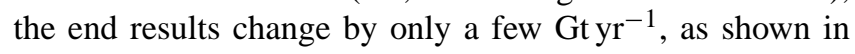

Table SM1, even when considering the difference between EA and WA. This provides evidence that the LPZ GIA bias correction successfully removes the $\mathrm{mm}^{-1} \mathrm{r}^{-1}$-level biases present in the degree one coefficients, regardless of which set of coefficients is used.

The LPZ bias correction also allows each solution to be compared more equivalently, since the bias contributors which are removed may be different for each case. The primary consequence for using the LPZ in this way is that the GIA solutions created become regional to Antarctica, and 
therefore cannot be used to estimate global GIA effects, such as the far-field GIA signal from the Northern Hemisphere. Second, if any genuine GIA over the LPZ does exist, then this would erroneously bias the empirically derived rates from the combination approach; however, as mentioned already, any error of this kind is believed to be much lower than that introduced by the various other (imprecisely known) bias contributors.

\section{Combination results}

The geographical plots of a select set of the resulting GIA models created from the LPZ calibration approach are shown in Fig. 8 (the full set of plots can be found in Fig. SM5 of the Supplement). The corresponding mass change values are provided in Table 2, expressed in total gigatons per year

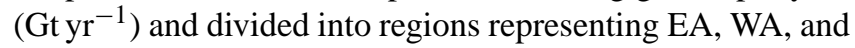
the total Antarctic Ice sheet (AIS), following the grounding lines defined by Zwally et al. (2012) (extended outwards by $400 \mathrm{~km}$ to account for the smoothing). By multiplying the uplift rates derived from Eq. (3) by the density of rock, the resulting empirical GIA mass change rates were then subtracted from the total mass change estimated from GRACE to derive a corresponding ice mass change value, also shown in Table 2. Since the earlier LPZ GIA bias was estimated using all components in Eq. (3) (i.e., including SMB, surface heights, and GRACE), in order to compute the ice mass change estimates in a consistent manner, a separate LPZ bias was estimated for only GRACE, i.e., the "LPZ GRACE bias", the values of which are shown in Table 2 in units of EWH. Again, this is done to ensure that the mean value of mass change over the LPZ is set to zero.

As mentioned earlier, the altimetry and climate data were only used over the grounded ice sheet since the hydrostatic equilibrium assumed for the floating ice shelves would not introduce any mass changes over these regions. This means that the GRACE data is primarily responsible for estimating the GIA signal over the ice shelves. In addition, the ocean mass change over the ice shelves was assumed to be small compared to the mass changes associated with the solid earth uplift, so these effects were not directly treated in this study. To verify this claim, the ocean mass change over the entire $400 \mathrm{~km}$ extended integration area was computed using the ocean mass change predictions from Bamber and Riva (2010), which includes the effects of self-gravitation. The total mass change over the entire Antarctic coastal region (i.e., within the $400 \mathrm{~km}$ zone) was only $4.5 \mathrm{Gt} \mathrm{yr}^{-1}$, confirming that the impact is small.

\subsection{Uncertainty analysis}

Errors in the empirical GIA and ice mass change estimates from the combination approach were computed using formal error propagation techniques, resulting in what are be- lieved to be realistic error uncertainties. Where possible, uncertainties provided for the individual input sources were used, while for other sources certain assumptions were made, the details of which are outlined below.

For the GRACE data, the uncertainties were derived using formal error propagation techniques and the publicly available calibrated errors provided by the CSR for each monthly solution, along with the uncertainties provided with the degree one and $\mathrm{C}_{2,0}$ coefficients. The calibrated errors were first propagated into EWH using the functional model described by Wahr et al. (1998). These errors were in turn propagated onto the trend component, using the same parameterization described earlier in Sect. 3.1. Though not shown, the GRACE errors do have a latitudinal dependency to them, but for Antarctica they are relatively uniform at approximately $1-1.5 \mathrm{~mm} \mathrm{yr}^{-1} \mathrm{EWH}$. It is important to note that the errors for GRACE are assumed to be the same for all solutions evaluated, which is a source of future refinement for the combination approach. The errors for the ICESat trends made use of the EVUW-scaled uncertainties discussed in Sect. 3.2, which are shown in Fig. 3b. Note that neither the GRACE nor ICESat trends account for autocorrelation in their time series (Ferguson et al., 2004; Williams et al., 2014), so the uncertainties used here can be considered as lower bound estimates. The FDM provided has associated uncertainties, as shown in Fig 6b; however, the SMB information used to determine $\dot{m}_{\text {firn }}$ in Eq. (3) does not have estimated uncertainties, so a standard deviation of $10 \%$ of the value for each grid point was used as a conservative estimate, similar to that employed by Rignot et al. (2008). For the rock densities, a standard deviation representing $100 \mathrm{~kg} \mathrm{~m}^{-3}$ of the value for each grid point was assumed, representing a $33 \%$ uncertainty in the difference between the $4000 \mathrm{~kg} \mathrm{~m}^{-3}$ upper range used and the average value of $3700 \mathrm{~kg} \mathrm{~m}^{-3}$ proposed by Wahr et al. (2000). Likewise, for the surface density value used when treating the differences between ICESat and the FDM, a $10 \%$ standard deviation was also used per grid point.

The aforementioned input data uncertainties were then formally propagated using Eq. (3) to generate total uncertainties for the three major mass change quantities (total mass change, GIA-related mass change, and ice mass change) for EA, WA, and the AIS. The uncertainties for the AIS were computed by taking the square root of the sum of squares of the EA and WA uncertainties. This is consistent with the analysis done as part of the recent Ice Sheet Mass Balance Inter-comparison Exercise (IMBIE) (Shepherd et al., 2012), and is justified by the fact that the primary signals in EA and WA are sufficiently separated for their errors to be treated as independent of each other. These results are summarized in the last row of Table 2, with the geographical variation of the uncertainties shown in Fig. 9. The GIA uncertainties $(1-\sigma)$ over the AIS are $40 \mathrm{Gt} \mathrm{yr}^{-1}$, with the regions of higher uncertainties located in the areas most expected, such as the Amundsen Sea sector (ASE) and Wilkes/Adelie Land (WAL), correlating to the regions of highest uncertainty in 


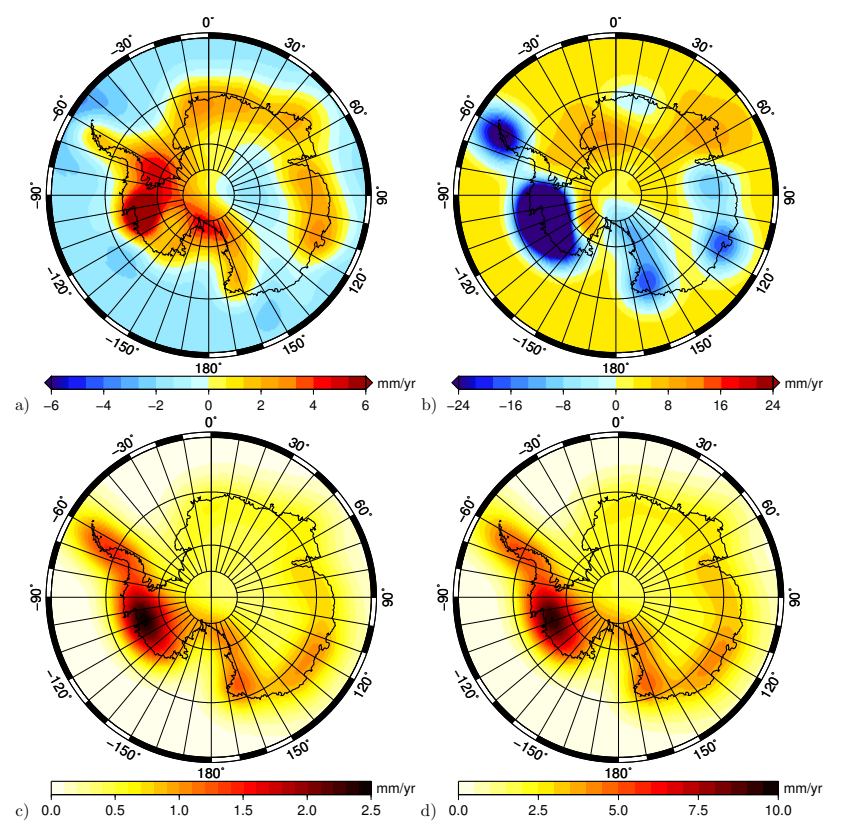

Fig. 9. Estimates $(\mathbf{a}, \mathbf{b})$ and uncertainties $(\mathbf{c}, \mathbf{d})$ for the empirically derived GIA rates $(\mathbf{a}, \mathbf{c})$ in $\mathrm{mm} \cdot \mathrm{yr}^{-1}$ and ice mass change rates (b, d) in $\mathrm{mm} \mathrm{EWH} \cdot \mathrm{yr}^{-1}$, using the representative case CSR RL04 DDK3.

the SMB and altimetry data sets. The ice mass change estimates are relatively well defined for WA at $22 \mathrm{Gt} \mathrm{yr}^{-1}$, with more uncertainty over EA, due primarily to the much larger surface area involved. In general, the ice mass change uncertainties match those of the IMBIE study, as well as other recent studies (King et al., 2012; Jacob et al., 2012). Uncertainty levels for GIA uplift rates are inherently difficult to quantify with current modeling techniques, and this is therefore one of the strengths of the data-driven approach. A more detailed discussion on the implications of these uncertainties on the results will be provided in the next sections.

\subsection{Comparisons with GPS ground stations}

To gain more insight into the performance of the estimated GIA rates as well as to ensure an equal comparison with existing GIA models, the GPS rates were compared to several variants of the estimated GIA uplift rates. The first approach uses the same WRMS calculation as are described by Eqs. (5) and (6), using the empirical rates corrected with the LPZ GIA bias described earlier, along with the estimated GPS and GIA uncertainties. Both the full 35-station set of GPS stations were used, as well as a smaller subset of 29 stations. The 29-station subset was chosen to remove the influence that stations on Graham Land (GRA) might have on the WRMS calculations as well as on two other stations which showed vertical rates with large differences $\left(>5 \mathrm{~mm} \mathrm{yr}^{-1}\right)$, or were opposite in sign, to neighboring GPS sites. GRA is a particularly dynamic region, and there are many factors that
Table 3. Comparison of estimated GIA rates with GPS vertical rates, using the uncertainties for both the GPS and GIA uplift rates in the WRMS calculations.

\begin{tabular}{lcc}
\hline Solution & \multicolumn{2}{c}{ WRMS } \\
\hline $\begin{array}{c}\text { 29-GPS-station set } \\
\mathrm{mm} \mathrm{yr}^{-1}\end{array}$ & $\begin{array}{c}\text { 35-GPS-station set } \\
\mathrm{mm} \mathrm{yr}^{-1}\end{array}$ \\
\hline CSR RL04 & 1.9 & 2.1 \\
CSR RL04 DDK3 & 1.9 & 2.1 \\
CSR RL05 & 1.8 & 2.1 \\
CSR RL05 DDK5 & 1.8 & 2.1 \\
CSR RL05 Reg & 1.8 & 2.1 \\
GFZ RL04 & 2.1 & 2.2 \\
GFZ RL04 DDK3 & 2.0 & 2.1 \\
GFZ RL05 & 1.9 & 2.2 \\
GFZ RL05 DDK5 & 1.8 & 2.1 \\
DMT-1b & 1.8 & 2.0 \\
\hline
\end{tabular}

could impact the comparison of the GPS and derived GIA rates (Scambos et al., 2004; Thomas et al., 2011). Examples include potentially strong elastic effects on the GPS stations, the fact that ICESat is relatively data poor in this region, and the ability of GRACE to resolve the mass change of narrow north-south oriented features. The WRMS comparisons for both sets of GPS stations are shown in Table 3, with the stations excluded in the 29-station subset designated by square symbols in Fig. 10.

The results shown in Table 3 are useful for evaluating the performance of the various individual cases computed from the combination approach, primarily because the uncertainty of the resulting GIA rates can be used in the WRMS calculation. For comparisons of the empirically derived GIA rates to those from existing GIA models, the uncertainties of these models are not always available. Therefore, the comparisons with the GIA models were handled slightly differently, with the intention of making the comparisons more equivalent. The individual assumptions and choice of Earth model parameters for each of the models is different, and again may result in a bias offset with the observed GPS rates. To account for these, a bias term was estimated and subtracted between the GPS and modeled-GIA rates before the WRMS was computed. This bias was estimated using nonuniform weights based on the GPS station uncertainties discussed in Sect. 3.4. A similar systematic bias term was also estimated for the empirical rates from the combination approach, and was removed in addition to the LPZ-bias term discussed previously. As shown in Table 4, the average systematic bias magnitude is approximately $1 \mathrm{~mm} \mathrm{yr}^{-1}$ and has an estimated uncertainty of $\sim 0.3 \mathrm{~mm} \mathrm{yr}^{-1}$, demonstrating the bias to be statistically significant. The removal of the GPS bias serves to reduce all solutions to the same frame as the GPS network, and ideally allows the WRMS values computed to reflect the spatial correlation with the station displacements and not additional systematic differences such as global reference 

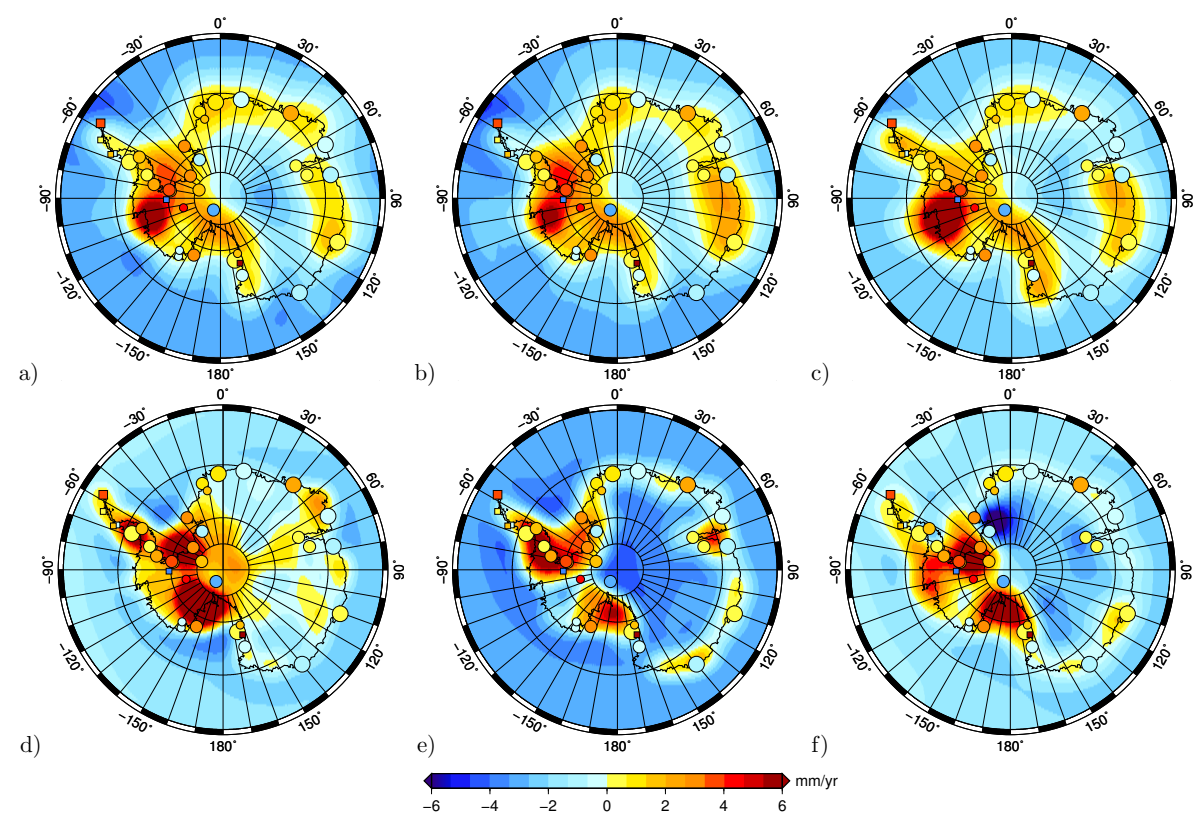

Fig. 10. Comparison of the 35-station WRMS of the residuals between the vertical rates from the GPS stations and the uplift rates derived from the following empirical/modeled cases: (a) CSR RL04 DDK3, (b) CSR RL05 Reg, (c) DMT-1b, (d) ICE-5G, (e) IJ05, and (f) W12a. Note that, for these comparisons, a systematic bias is removed from the empirical/modeled rates with respect to the GPS network (see text for details).

frame differences or far-field model assumptions. In addition to the systematic bias correction, because model uncertainties are not provided for all models, only the uncertainties of the GPS stations were used in the WRMS calculations. This is equivalent to setting $\sigma_{\text {rock }}$ to zero in Eq. (6).

The empirical rates were compared to the rates predicted from three recent GIA models: the ICE-5G model (Peltier, 2004) ${ }^{1}$, the IJ05 model (Ivins and James, 2005), and the W12a model (Whitehouse et al., 2012) ${ }^{2}$. The Simon et al. (2010) revision of the IJ05 model was used (full sealevel equation and global ocean loading) with no Antarctic continent load change since $800 \mathrm{BP}$. Also included in the comparisons were the results from the earlier study by Riva et al. (2009), termed here Riva09. As before, comparisons were made using both the full 35- and 29-station data sets. The results are listed in Table 4 and show both the original WRMS and bias-corrected WRMS values. For the GIA rates derived from traditional modeling techniques, it is recognized that the choice of different earth, ice-loading, or other parameters will result in more than just a uniform bias correction, and the errors involved may have some spatial variability; however, without more detailed knowledge of these variations, it was felt that removing these first-order effects with a bias correction was more appropriate than not correcting for any systematic differences at all. Note also that the WRMS values shown for Riva09, IJ05 and ICE-5G are

\footnotetext{
1 www.psmsl.org/train_and_info/geo_signals/gia/peltier/

2 www.dur.ac.uk/pippa.whitehouse/
}

corrections to the values shown in Thomas et al. (2011), and partially repeated in Whitehouse et al. (2012), due to an error in their WRMS calculations (the updated values do not affect the ranking of these models in these earlier works). To visually examine the differences, a selection of three empirical solutions representing the various GRACE processing variations (CSR RL04 DDK5, CSR RL05 Reg, and DMT1-b) are plotted in Fig. 10 alongside the three GIA models, with all figures representing the 35 -station case after adjustment for the systematic bias. For reference, plots of the original unadjusted GIA models can be found in Fig. S6 of the Supplement.

\subsection{Discussion}

Several observations can be made when examining the results of the combinations and the comparisons with the GPS vertical displacements. First, the spatial pattern of the empirically derived rates is mostly similar across all solutions, with most of the variations involving differences in magnitude. For example all solutions indicate sizeable uplift in WA and a slight degree of subsidence for most of the EA interior. Similar patterns of subsidence are also observed in the W12a and IJ05 models. The same can be said for the uplift beneath the Filchner Ronne Ice shelf (FRIS) and Ross Ice shelf (RIS). The magnitude of this uplift does vary depending on the solution considered (including models), but in general the geographical location of the signal is common to all cases. It is worth noting here again that any height changes over the 
Table 4. Comparison of estimated GIA rates with GPS vertical rates, using only uncertainties for the GPS uplift rates in the WRMS calculations.

\begin{tabular}{|c|c|c|c|c|c|c|}
\hline \multirow[b]{2}{*}{ Solution } & \multicolumn{3}{|c|}{ 29-GPS-station set } & \multicolumn{3}{|c|}{ 35-GPS-station set } \\
\hline & WRMS & $\begin{array}{c}\text { Systematic } \\
\text { bias }\end{array}$ & $\begin{array}{c}\text { Bias-corr. } \\
\text { WRMS }\end{array}$ & WRMS & $\begin{array}{l}\text { Systematic } \\
\text { bias }\end{array}$ & $\begin{array}{c}\text { Bias-corr. } \\
\text { WRMS }\end{array}$ \\
\hline CSR RL04 & 1.7 & 1.3 & 1.2 & 1.9 & 1.2 & 1.5 \\
\hline CSR RL04 DDK3 & 1.7 & 1.3 & 1.1 & 1.9 & 1.2 & 1.4 \\
\hline CSR RL05 & 1.6 & 0.9 & 1.4 & 1.8 & 0.8 & 1.6 \\
\hline CSR RL05 DDK5 & 1.6 & 0.9 & 1.3 & 1.8 & 0.8 & 1.6 \\
\hline CSR RL05 Reg & 1.6 & 0.9 & 1.3 & 1.8 & 0.8 & 1.6 \\
\hline GFZ RL04 & 2.1 & 1.5 & 1.4 & 2.1 & 1.4 & 1.6 \\
\hline GFZ RL04 DDK3 & 1.8 & 1.4 & 1.2 & 1.9 & 1.3 & 1.4 \\
\hline GFZ RL05 & 1.6 & 0.8 & 1.4 & 1.9 & 0.6 & 1.7 \\
\hline GFZ RL05 DDK5 & 1.6 & 0.8 & 1.4 & 1.8 & 0.6 & 1.7 \\
\hline DMT-1b & 1.7 & 0.9 & 1.4 & 1.8 & 0.9 & 1.6 \\
\hline IJ05 & 3.4 & 2.5 & 2.2 & 3.4 & 2.4 & 2.4 \\
\hline ICE-5G & 3.0 & 1.2 & 2.8 & 3.0 & 1.1 & 2.8 \\
\hline W12a & 2.2 & 1.4 & 1.7 & 2.3 & 1.3 & 1.8 \\
\hline Riva09 & 2.1 & 1.6 & 1.4 & 2.2 & 1.5 & 1.7 \\
\hline
\end{tabular}

ice shelves were ignored since the hydrostatic equilibrium of the floating ice would not result in changes to the total column mass. Therefore, the empirical GIA rates under the ice shelves were estimated almost entirely from the GRACE data, under the assumption that ocean mass changes in the region were negligible.

In the ASE, the empirical models indicate higher rates of uplift than those typically predicted in this area by the other models based on ice history reconstruction. There are several plausible reasons that might explain this signal. The first is that genuine GIA uplift is taking place in this area, as suggested by a recent study by Groh et al. (2012); however, the in situ data used to validate the results of this study were derived from only two seasonal GPS campaigns, so these data have large uncertainty and need to be confirmed by additional long-term GPS measurements. The error analysis for the combination approach, shown in Fig. 9c, produced a 1- $\sigma$ uncertainty level of approximately $2 \mathrm{~mm} \mathrm{yr}^{-1}$ for the ASE, making the $6+\mathrm{mm} \mathrm{yr}^{-1}$ uplift rates shown by all of the empirical rates in Fig. 8 statistically significant (i.e., greater than the $95 \%$ confidence interval), providing additional evidence that the uplift observed is real. The earlier results obtained by Riva et al. (2009) do not show the same degree of uplift in the ASE (see Supplement Fig. S6), even though a similar technique was employed. The difference can be explained by the fact that the new approach presented here considers firn compaction and surface processes via the FDM and SMB estimates from RACMO2. The Riva et al. (2009) study did not account for any surface height or density change caused by the sizeable amount of accumulation $\left(>10 \mathrm{~cm} \mathrm{yr}^{-1}\right.$, see Fig. 6) that takes place in the ASE, and assigned all volume loss a density of ice. Doing so generates a lower mass-loss rate for the region; however, now that these surface processes are taken into account, the altimetry-derived mass loss is greater for the ASE, resulting in a positive mass offset when compared to GRACE; this is interpreted as GIA uplift in the inversion.

That the traditional models based on ice history reconstruction do not show the same magnitude of signals as those estimated from the empirical approach may be largely due to the fact that these models do not typically consider ice load changes that have occurred in the past 1000 years or so. Nield et al. (2012) showed in their study that large, presentday changes in ice loading can have a noticeable impact on GIA uplift rates, particularly in regions of low viscosity, such as the Antarctic Peninsula.

Naturally, there are other plausible explanations for the observed uplift in the ASE. It is possible that the gridded ICESat height change maps may overestimate the total volume loss in the ASE or that GRACE is underestimating the mass loss. In either of these cases, the positive mass differential unaccounted for would be interpreted as GIA uplift in the combination. Alternatively, the SMB estimates could be overestimating the amount of accumulation in the region, again causing the positive mass differential with what GRACE observes to be treated as GIA uplift. While no long-term GPS vertical rates are currently available in the ASE, there have been a handful of permanent stations recently installed which will help validate these claims ${ }^{3}$. These future GPS measurements should also help to clarify the magnitude and spatial extent of the uplift, as some of the GIA solutions predict more widespread uplift than others. In particular, the RL04based solutions tend to produce a larger extent of GIA uplift over the ASE than the RL05-based solutions, while the RL05 solutions indicate more uplift over the FRIS.

\footnotetext{
${ }^{3}$ www.polenet.com
} 
In the Philippi/Denman (PD) sectors, the empirical GIA rates show a stronger uplift pattern than those found in the GIA models (Figs. 8 and Fig. S6 in the Supplement). It is not believed that the estimated uplift is the result of any unmodeled accumulation, as the ICESat and FDM results agree well in this region and the positive mass anomaly in the area is consistently observed in the GRACE solutions (Fig. 1), in particular in the regularized solutions, which tend to have higher spatial resolution. Also, the uncertainty analysis does not suggest any unusual circumstances in the area. Unfortunately, the comparisons with the GPS rates are inconclusive, since the few stations in the area are located on the perimeter of the region in question. As such, the presence of genuine GIA uplift in the region will require more investigation before this can be confirmed.

As the methodology and comparisons described earlier make use of a number of different biases, it is useful to review these again for clarification. The first of the biases computed was for the ICESat data, to correct for known systematic rate offsets in the height measurements, and it was computed over the LPZ under the assumption that very little surface height change takes place there. Later, the LPZ is used again as a calibration zone to estimate an offset observed in the empirical GIA rates estimated from the combination approach. The presence of this offset is likely due to factors inherent in the data sets used, e.g., geocenter motion, $\mathrm{C}_{2,0}$, etc., which can each introduce mm-level errors. The mean GIA uplift rate (emphasis on "mean") over the LPZ was assumed to be much smaller than these errors, so an empirical LPZ GIA bias was computed over this region for every empirical GIA solution and subtracted. Therefore, any reference to the empirical GIA solutions, including those in the tables and figures, imply that this LPZ GIA bias has already been removed. A LPZ GIA bias was not computed or removed from any of the modeled GIA data sets, as the reasoning behind the bias calculation was only relevant to the empirically derived GIA uplift estimates; however, a separate offset correction was applied for the GPS comparisons. This was because a systematic offset was observed between the modeled/empirical GIA rates and those observed from the GPS stations, which was presumably due to differences in processing, e.g., reference frames and other effects. For this systematic offset, all GPS stations were used, and a unique bias was computed for each comparison made, with the intention of making the WRMS comparisons as equivalent as possible. For the empirical GIA rates this systematic bias was applied in addition to the LPZ GIA bias, while for the modeled GIA data sets only the systematic bias was used.

Looking at the WRMS values in Table 3, most solutions compare well with each other, with differences only at the $0.1-0.2 \mathrm{~mm} \mathrm{yr}^{-1}$ level. Again, these were computed using only the LPZ GIA bias calibration while taking into consideration the uncertainty of both the GIA and GPS stations. When examining Table 4 , which only considers GPS station uncertainties and removes an additional systematic bias term, more variation in the results can be seen. The CSR RL04 DDK3 solution shows the lowest WRMS after the systematic bias is removed at $1.1 \mathrm{~mm} \mathrm{yr}^{-1}$, but the results of the other regularized solutions for both RL04 and RL05 are comparable, particularly for the 35-station set. It is interesting to note that the RL04 solutions have a larger systematic bias correction than the RL05 solutions, which is likely due to the difference in reference frames used in the GPS and RL04 GRACE data processing. In nearly all cases, the 29-station results are lower than those of the 35-station set. When comparing the empirical results to the model results, either with or without the systematic bias removed, the empirical rates show consistently lower values, with the W12a model having the closest similarity in terms of WRMS.

Regarding the ice mass change estimates, the values for all cases were relatively consistent. This is primarily a consequence of the fact that the surface height change information was fixed to that determined by the altimetry and FDM data sets. In the combination, this essentially determines the variability of the firn and ice layers, forcing any variation in mass change seen by GRACE to go into the GIA estimates. The average empirically derived ice mass change rate of $-100 \pm 44 \mathrm{Gt} \mathrm{yr}^{-1}$ (EA: $5 \pm 38$, WA: $-105 \pm 22$ ) from this study falls within the $1-\sigma$ range of predictions over the entire AIS from the recent IMBIE study (Shepherd et al., 2012) for a similar time frame $(-57 \pm 50$, October 2003-December 2008, using W12a and IJ05_R2; $-137 \pm 49 \mathrm{Gt} \mathrm{yr}^{-1}$ using ICE-5G), as well as recent studies by Sasgen et al. (2013) $(-114 \pm 23,2003-2012)$, Jacob et al. (2012) $(-165 \pm 36,1-$ $\sigma$, using ICE-5G), and King et al. (2012) ( $-68.7 \pm 17.5$, using W12a). In EA, the empirical results were closest to Sasgen et al. (2013) $(26 \pm 13)$, and were still within $1-\sigma$ of Shepherd et al. (2012) ( $35 \pm 40)$, but showed differences with King et al. (2012) $(60.2 \pm 12.8)$. Similarly, for WA, the empirical GIA results were still within the $1-\sigma$ range of Shepherd et al. (2012) ( $-68 \pm 23)$, but were more similar to those from King et al. (2012) $(-117.7 \pm 9.2)$ and Sasgen et al. (2013) $(-116 \pm 15)$.

\section{Conclusions}

This study revisited the approach developed by Riva et al. (2009) for estimating present-day GIA and ice mass change using a combination of satellite altimetry and gravimetry. An updated and extended ICESat surface height change map was combined with a range of different GRACE solutions, along with an advanced regional atmospheric climate model and associated FDM. New ICESat surface trends were computed, for the first time over Antarctica, using an overlapping footprint approach, complete with a custom set of campaign biases. The FDM and SMB estimates derived from RACMO2 addressed a key limitation in the earlier study and enabled the combination approach to treat variations in surface height and density due to firn compaction and 
other surface processes. Another key element of the analysis was the calibration of the results to a low-precipitation zone in East Antarctica, which helped reduce the impact of the mm-level (unknown) biases inherent to the satellite input data sets. Lastly, knowledge of the uncertainties for the various input data sources provided the opportunity to generate realistic error assessments of both the GIA and ice mass change estimates through formal error propagation methods. The total empirical GIA mass change estimates for the AIS ranged from 53 to $103 \mathrm{Gt} \mathrm{yr}^{-1}$ (EA: 33-60 $\mathrm{Gt} \mathrm{yr}^{-1}$; WA: 18$48 \mathrm{Gt} \mathrm{yr}^{-1}$ ), depending on the GRACE solution used, with an estimated uncertainty of $\pm 40 \mathrm{Gt} \mathrm{yr}^{-1}$ (EA: \pm 34 ; WA: \pm 21 ). Over the time frame February 2003-October 2009, the corresponding ice mass change averaged $-100 \pm 44 \mathrm{Gt} \mathrm{yr}^{-1}$ (EA: $5 \pm 38 \mathrm{Gt} \mathrm{yr}^{-1}$, WA: $-105 \pm 22 \mathrm{Gt} \mathrm{yr}^{-1}$ ) across all solutions. This makes the total Antarctic mass change (ice and solid earth) over this 2003-2009 time frame range from $2 \mathrm{Gt} \mathrm{yr}^{-1}$ to $-47 \mathrm{Gt} \mathrm{yr}^{-1}$. Furthermore, the mean total Antarctic mass change for the RL04-based solutions is $-8.4 \pm 8.5 \mathrm{Gt} \mathrm{yr}^{-1}$, and $-39.8 \pm 8.5 \mathrm{Gt} \mathrm{yr}^{-1}$ for RL05, highlighting the differences between the two data releases. The empirically derived GIA rates show some noticeable differences to other recent GIA models derived using the more traditional ice history reconstruction approach, such as in the ASE and the PD sectors, but also show many similarities, such as the general subsidence in East Antarctica and uplift beneath the Ross and Filchner Ronne Ice shelf. Some of the disagreement between forward-modeled and empirically derived uplift rates may be due to the fact the forward GIA models do not typically consider ice load changes during the last 1000 years, and this signal may be significant. The empirical GIA rates generated from this approach showed good overall agreement with an independent set of GPS-derived vertical rates, although there are no long-term GPS records in some of the suspected uplift zones, such as the ASE and PD sectors, so the estimated vertical rates in these areas cannot currently be verified. Nonetheless, the results from the combination approach demonstrate that the technique has the potential to reduce the uncertainty surrounding both Antarctic GIA and ice mass change estimates and provide new insights into the impact that recent ice load changes may have on present-day uplift rates.

\section{Supplementary material related to this article is available online at http://www.the-cryosphere.net/8/743/ 2014/tc-8-743-2014-supplement.pdf.}

Acknowledgements. The authors would like to thank P. Ditmar and H. Hashemi Farahani for providing the DMT solutions, H. Save for the CSR regularized solutions, and J. Kusche for the DDK solutions. Additional thanks go to P. Whitehouse for the W12a GIA model, Erik Ivins for the IJ05 model, and Richard Peltier for the ICE-5G model. All geographical plots were produced using the Generic Mapping Tools (GMT). This study was partially funded by the Division for Earth and Life Sciences (ALW) with financial aid from the New Netherlands Polar Programme (NNPP) of the Netherlands Organization for Scientific Research (NWO). M. A. King is a recipient of an Australian Research Council Future Fellowship (project number FT110100207). The ICESat data was provided by the National Snow and Ice Data Center (NSIDC), and the unconstrained GRACE solutions were obtained from the Physical Oceanography Distributed Active Archive Center (PO.DAAC) at the NASA Jet Propulsion Laboratory, Pasadena, CA.

Edited by: E. Larour

\section{References}

Bamber, J. and Riva, R.: The sea level fingerprint of recent ice mass fluxes, The Cryosphere, 4, 621-627, doi:10.5194/tc-4-621-2010, 2010.

Bettadpur, S.: CSR Level-2 Processing Standards Document for Product Release 04 GRACE 327-742, Center for Space Research, 3.1 Edn., http://podaac.jpl.nasa.gov/gravity/ grace-documentation (last accessed 18 April 2014), 2007.

Borsa, A. A., Moholdt, G., Fricker, H. A., and Brunt, K. M.: A range correction for ICESat and its potential impact on ice-sheet mass balance studies, The Cryosphere, 8, 345-357, doi:10.5194/tc-8345-2014, 2014.

Chambers, D. P. and Bonin, J. A.: Evaluation of Release-05 GRACE time-variable gravity coefficients over the ocean, Ocean Sci., 8, 859-868, doi:10.5194/os-8-859-2012, 2012.

Chen, J. L., Wilson, C. R., Blankenship, D. D., and Tapley, B. D.: Antarctic mass rates from GRACE, Geophys. Res. Lett., 33, L11502, doi:10.1029/2006GL026369, 2006.

Cheng, M. and Tapley, B. D.: Variations in the Earth's oblateness during the past 28 years, J. Geophys. Res., 109, B09402, doi:10.1029/2004JB003028, 2004.

Cheng, M., Ries, J. C., and Tapley, B. D.: Variations of the Earth's figure axis from satellite laser ranging and GRACE, J. Geophys Res.-Earth, 116, B01409, doi:10.1029/2010JB000850, 2011.

Ewert, H., Popov, S. V., Richter, A., Schwabe, J., Scheinert, M., and Dietrich, R.: Precise analysis of ICESat altimetry data and assessment of the hydrostatic equilibrium for subglacial Lake Vostok, East Antarctica, Geophys. J. Int., 191, 557-568, doi:10.1111/j.1365-246X.2012.05649.x, 2012.

Ferguson, A., Davis, C., and Cavanaugh, J.: An autoregressive model for analysis of ice sheet elevation change time series, Geoscience and Remote Sensing, IEEE Trans. Geosci. Remote Sens., 42, 2426-2436, doi:10.1109/TGRS.2004.836788, 2004.

Groh, A., Ewert, H., Scheinert, M., Fritsche, M., Rülke, A., Richter, A., Rosenau, R., and Dietrich, R.: An investigation of Glacial Isostatic Adjustment over the Amundsen Sea sector, West Antarctica, Global Planet. Change, 98-99, 45-53, doi:10.1016/j.gloplacha.2012.08.001, 2012.

Gunter, B., Urban, T., Riva, R., Helsen, M., Harpold, R., Poole, S., Nagel, P., Schutz, B., and Tapley, B.: A comparison of coincident GRACE and ICESat data over Antarctica, J. Geodesy, 83, 10511060, doi:10.1007/s00190-009-0323-4, 2009.

Gunter, B., Riva, R., Urban, T., Harpold, R., Schutz, B., Nagel, P., and Helsen, M.: Evaluation of GRACE and ICESat Mass Change Estimates Over Antarctica, in: Gravity, Geoid and Earth Observation, edited by: Mertikas, S. P., vol. 135 of International Asso- 
ciation of Geodesy Symposia, 563-569, Springer Berlin Heidelberg, doi:10.1007/978-3-642-10634-7_75, 2010.

Horwath, M. and Dietrich, R.: Signal and error in mass change inferences from GRACE: the case of Antarctica, Geophys. J. Int., 177, 849-864, doi:0.1111/j.1365-246X.2009.04139.x, 2009.

Hughes, G. B. and Chraibi, M.: Calculating Ellipse Overlap Areas, http://arxiv.org/abs/1106.3787 (last access: 18 April 2014), 2011.

Ivins, E. R. and James, T. S.: Antarctic glacial isostatic adjustment: a new assessment, Antarct. Sci., 17, 541-553, 2005.

Jacob, T., Wahr, J., Pfeffer, W., and Swenson, S.: Recent contributions of glaciers and ice caps to sea level rise, Nature, 482, 514-518, 2012.

Kaspers, K. A., van de Wal, R. S. W., van den Broeke, M. R., Schwander, J., van Lipzig, N. P. M., and Brenninkmeijer, C. A. M.: Model calculations of the age of firn air across the Antarctic continent, Atmos. Chem. Phys., 4, 1365-1380, doi:10.5194/acp4-1365-2004, 2004.

King, M. A., Bingham, R. J., Moore, P., Whitehouse, P. L., Bentley, M. J., and Milne, G. A.: Lower satellite-gravimetry estimates of Antarctic sea-level contribution, Nature, 491, 586-589, doi:10.1038/nature11621, 2012.

Klees, R., Revtova, E. A., Gunter, B. C., Ditmar, P., Oudman, E., Winsemius, H. C., and Savenije, H. H. G.: The design of an optimal filter for monthly GRACE gravity models, Geophys. J. Int., 175, 417-432, doi:10.1111/j.1365-246X.2008.03922.x, 2008.

Kusche, J.: Approximate decorrelation and non-isotropic smoothing of time-variable GRACE-type gravity field models, J. Geodesy, 81, 733-749, doi:10.1007/s00190-007-0143-3, 2007.

Lenaerts, J. T. M., van den Broeke, M. R., van de Berg, W. J., van Meijgaard, E., and Kuipers Munneke, P.: A new, high-resolution surface mass balance map of Antarctica (1979-2010) based on regional atmospheric climate modeling, Geophys. Res. Lett., 39, L04501, doi:10.1029/2011GL050713, 2012.

Ligtenberg, S. R. M., Helsen, M. M., and van den Broeke, M. R.: An improved semi-empirical model for the densification of Antarctic firn, The Cryosphere, 5, 809-819, doi:10.5194/tc-5-809-2011, 2011.

Liu, X., Ditmar, P., Siemes, C., Slobbe, D., Revtova, E., Klees, R., Riva, R., and Zhao, Q.: DEOS Mass Transport model (DMT-1) based on GRACE satellite data: methodology, validation, and application to estimating the ice mass balance of Greenland, Geophys. J. Int., 181, 769-788, 2010.

Nield, G. A., Whitehouse, P. L., King, M. A., Clarke, P. J., and Bentley, M. J.: Increased ice loading in the Antarctic Peninsula since the 1850 s and its effect on glacial isostatic adjustment, Geophys. Res. Lett., 39, L17504, doi:10.1029/2012GL052559, 2012.

Peltier, W.: Global glacial isostasy and the surface of the ice-age Earth: The ICE-5G (VM2) Model and GRACE, Annu. Rev. Earth Pl. Sc., 32, 111-149, 2004.

Pritchard, H. D., Arthern, R. J., Vaughan, D. G., and Edwards, L. A.: Extensive dynamic thinning on the margins of the Greenland and Antarctic ice sheets, Nature, 461, 971-975, doi:10.1038/nature08471, 2009.

Rignot, E., Bamber, J., van den Broeke, M., Davis, C., Li, Y., van de Berg, W., and van Meijgaard, E.: Recent Antarctic ice mass loss from radar interferometry and regional climate modelling, Nat. Geosci., 1, 106-110, doi:10.1038/ngeo102, 2008.

Riva, R. E. M., Gunter, B. C., Urban, T. J., Vermeersen, B. L. A., Lindenbergh, R. C., Helsen, M. M., Bamber, J. L., van den Broeke, M. R., and Schutz, B. E.: Glacial Isostatic Adjustment over Antarctica from combined ICESat and GRACE satellite data, Earth Planet. Sc. Lett., 288, 516-523, doi:10.1016/j.epsl.2009.10.013, 2009.

Sasgen, I., Konrad, H., Ivins, E. R., Van den Broeke, M. R., Bamber, J. L., Martinec, Z., and Klemann, V.: Antarctic ice-mass balance 2003 to 2012: regional reanalysis of GRACE satellite gravimetry measurements with improved estimate of glacial-isostatic adjustment based on GPS uplift rates, The Cryosphere, 7, 1499-1512, doi:10.5194/tc-7-1499-2013, 2013.

Save, H., Bettadpur, S., and Tapley, B.: Reducing errors in the GRACE gravity solutions using regularization, J. Geodesy, 86, 695-711, doi:10.1007/s00190-012-0548-5, 2012.

Scambos, T. A., Bohlander, J. A., Shuman, C. A., and Skvarca, P.: Glacier acceleration and thinning after ice shelf collapse in the Larsen B embayment, Antarctica, Geophys. Res. Lett., 31, L18402, doi:10.1029/2004GL020670, 2004.

Seo, K.-W., Wilson, C. R., Chen, J., and Waliser, D. E.: GRACE's spatial aliasing error, Geophys. J. Int., 172, 41-48, doi:10.1111/j.1365-246X.2007.03611.x, 2008.

Shepherd, A., Ivins, E. R., A, G., Barletta, V. R., Bentley, M. J., Bettadpur, S., Briggs, K. H., Bromwich, D. H., Forsberg, R., Galin, N., Horwath, M., Jacobs, S., Joughin, I., King, M. A., Lenaerts, J. T. M., Li, J., Ligtenberg, S. R. M., Luckman, A., Luthcke, S. B., McMillan, M., Meister, R., Milne, G., Mouginot, J., Muir, A., Nicolas, J. P., Paden, J., Payne, A. J., Pritchard, H., Rignot, E., Rott, H., Sørensen, L. S., Scambos, T. A., Scheuchl, B., Schrama, E. J. O., Smith, B., Sundal, A. V., van Angelen, J. H., van de Berg, W. J., van den Broeke, M. R., Vaughan, D. G., Velicogna, I., Wahr, J., Whitehouse, P. L., Wingham, D. J., Yi, D., Young, D., and Zwally, H. J.: A Reconciled Estimate of Ice-Sheet Mass Balance, Science, 338, 1183-1189, doi:10.1126/science.1228102, 2012.

Siegfried, M., Hawley, R., and Burkhart, J.: High-Resolution Ground-Based GPS Measurements Show Intercampaign Bias in ICESat Elevation Data Near Summit, Greenland, IEEE T. Geosci. Remote, 49, 3393-3400, doi:10.1109/TGRS.2011.2127483, 2011.

Siemes, C., Ditmar, P., Riva, R., Slobbe, D., Liu, X., and Farahani, H.: Estimation of mass change trends in the Earth's system on the basis of GRACE satellite data, with application to Greenland, J. Geodesy, 87, 69-87, doi:10.1007/s00190-012-0580-5, 2013.

Simon, K., James, T., and Ivins, E.: Ocean loading effects on the prediction of Antarctic glacial isostatic uplift and gravity rates, $\mathrm{J}$ Geodesy, 84, 305-317, doi:10.1007/s00190-010-0368-4, 2010.

Slobbe, D., Lindenbergh, R., and Ditmar, P.: Estimation of volume change rates of Greenland's ice sheet from ICESat data using overlapping footprints, Remote Sens. Environ., 112, 4204-4213, doi:10.1016/j.rse.2008.07.004, 2008.

Strang, G. and Borre, K.: Linear Algebra, Geodesy, and GPS, Wellesley-Cambridge Press, Wellesley, MA, 1997.

Swenson, S. and Wahr, J.: Post-processing removal of correlated errors in GRACE data, J. Geophys. Res., 33, L08402, doi:10.1029/2005GL025285, 2006.

Swenson, S., Chambers, D., and Wahr, J.: Estimating Geocenter Variations from a Combination of GRACE and Ocean Model Output, J. Geophys. Res., 13, B08410, doi:10.1029/2007JB005338, 2008 
Thomas, I. D., King, M. A., Bentley, M. J., Whitehouse, P. L., Penna, N. T., Williams, S. D. P., Riva, R. E. M., Lavallee, D. A., Clarke, P. J., King, E. C., Hindmarsh, R. C. A., and Koivula, H.: Widespread low rates of Antarctic glacial isostatic adjustment revealed by GPS observations, Geophys. Res. Lett., 38, L22302, doi:10.1029/2011GL049277, 2011.

Thompson, P. F., Bettadpur, S. V., and Tapley, B. D.: Impact of short period, non-tidal, temporal mass variability on GRACE gravity estimates, Geophys. Res. Lett., 31, L06619, doi:10.1029/2003GL019285, 2004.

Urban, T. and Schutz, B. E.: ICESat sea level comparisons, Geophys. Res. Lett., 32, L23S10, doi:10.1029/2005GL024306, 2005.

Velicogna, I. and Wahr, J.: A method for separating Antarctic postglacial rebound and ice mass balance using future ICESat Geoscience Laser Altimeter System, Gravity Recovery and Climate Experiment, and GPS satellite data, J. Geophys. Res.-Earth, 107, ETG 20-1-ETG 20-11, doi:10.1029/2001JB000708, 2002.

Velicogna, I. and Wahr, J.: Time-variable gravity observations of ice sheet mass balance: Precision and limitations of the GRACE satellite data, Geophys. Res. Lett., 40, 3055-3063, doi:10.1002/grl.50527, 2013.

Wahr, J., Molenaar, M., and Bryan, F.: Time variability of the Earth's gravity field: Hydrological and oceanic effects and their possible detection using GRACE, J. Geophys. Res., 103, 3020530230, doi:10.1029/98JB02844, 1998.
Wahr, J., Wingham, D., and Bentley, C.: A method of combining ICESat and GRACE satellite data to constrain Antarctic mass balance, J. Geophys. Res., 105, 16279-16294, 2000.

Whitehouse, P. L., Bentley, M. J., Milne, G. A., King, M. A., and Thomas, I. D.: A new glacial isostatic adjustment model for Antarctica: calibrated and tested using observations of relative sea-level change and present-day uplift rates, Geophys. J. Int., 190, 1464-1482, doi:10.1111/j.1365-246X.2012.05557.x, 2012.

Williams, S. D., Moore, P., King, M. A., and Whitehouse, P. L.: Revisiting GRACE Antarctic ice mass trends and accelerations considering autocorrelation, Earth Planet. Sc. Lett., 385, 12-21, doi:10.1016/j.epsl.2013.10.016, 2014.

Zwally, J. H., Schutz, R., Bentley, C., Bufton, J., Herring, T., Minster, J., Spinhirne, J., and Thomas, R.: GLAS/ICESat L2 Antarctic and Greenland Ice Sheet Altimetry Data. Version 33. GLA12., Boulder, Colorado USA: National Snow and Ice Data Center, 2011.

Zwally, J. H., Giovinetto, M. B., Beckley, M. A., and Saba, J. L.: Antarctic and Greenland Drainage Systems, GSFC Cryospheric Sciences Laboratory, http://icesat4.gsfc.nasa.gov/cryo_data/ant_ grn_drainage_systems.php (last access: 18 April 2014), 2012. 